\title{
Antioxidant status and gut microbiota change in an aging mouse model as influenced by exopolysaccharide produced by Lactobacillus plantarum YW11 isolated from Tibetan kefir
}

\author{
Jian Zhang, Xiao Zhao, Yunyun Jiang, Wen Zhao, Ting Guo, Yongqiang Cao, Junwei Teng, Xiaona Hao, \\ Juan Zhao, and Zhennai Yang ${ }^{1}$ \\ Beijing Advanced Innovation Center for Food Nutrition and Human Health, Beijing Technology and Business University, Beijing 100048, China
}

\begin{abstract}
This study investigated the effect of exopolysaccharide (EPS) produced by Lactobacillus plantarum YW11 on the oxidative status and gut microbiota in an aging mouse model induced with D-galactose. The in vitro assay of the antioxidant activity of the EPS showed concentration-dependent $(0.25-3.0 \mathrm{mg} / \mathrm{mL})$ activities. At $3.0 \mathrm{mg} / \mathrm{mL}$, the EPS reached the highest scavenging activities with half maximal inhibitory concentration values against hydroxyl radicals at $75.10 \%$ and 1.22 $\mathrm{mg} / \mathrm{mL}$, superoxide anion at $62.71 \%$ and $1.54 \mathrm{mg} / \mathrm{mL}$, 2, 2-diphenyl-1-picrylhydrazyl at $35.11 \%$ and $0.63 \mathrm{mg} /$ $\mathrm{mL}$, and the maximal chelating rate on ferrous ion and the half-maximal chelating concentration of the EPS at $41.09 \%$ and $1.07 \mathrm{mg} / \mathrm{mL}$, respectively. High doses of EPS (50 mg/kg per day) effectively relieved the oxidative stress in the aging mice with increased levels of glutathione peroxidase, superoxide dismutase, catalase, and total antioxidant capacity in mice serum by 21.55 , $33.14,61.09$, and $38.18 \%$, respectively, and decreased malondialdehyde level from 11.69 to $5.89 \mathrm{mmol} / \mathrm{mL}$ compared with those in the untreated aging mice model. The analysis of pyrosequencing sequence data from the gut microbiota revealed that the EPS could recover the microbiota diversity and phylotypes decreased or eliminated by the D-galactose treatment. The EPS could selectively decrease the abundance of Flexispira (37.5 fold), and increase the abundance of Blautia (36.5 fold) and Butyricicoccus (9.5 fold), which correspondingly decreased the content of nitrogen oxides to $9.87 \%$ and increased the content of short-chain fatty acids by 2.23 fold, thereby improving the oxidative and health conditions of the host intestinal tract. Further correlation analysis of core-microbiota variation induced by different treatments showed a strong correlation with oxidative phenotypes [catalase, goodness of prediction
\end{abstract}

Received December 18, 2016.

Accepted March 30, 2017.

${ }^{1}$ Corresponding author: yangzhennai@th.btbu.edu.cn
$\left(\mathrm{Q}^{2}\right)=0.49$; total antioxidant capacity, $\mathrm{Q}^{2}=0.45 ;$ nitrogen oxides, $\mathrm{Q}^{2}=0.67$; short-chain fatty acids, $\mathrm{Q}^{2}$ $=0.55]$. The fermented milk with $L$. plantarum YW11 containing EPS also showed favorable antioxidant and gut microbiota regulating activities. The present finding provided new insights into the functional mechanism of probiotics bioactivity.

Key words: antioxidant, exopolysaccharide, fermented milk, gut microbiota

\section{INTRODUCTION}

Oxidative stress in living organisms can be caused by an increased load or accumulation of reactive oxygen species (ROS), which is generally associated with various physiological malfunctions and diseases, including immunomodulation (Park et al., 2015), aging (Li et al., 2016b), apoptosis (Formichi et al., 2016), cancer (Glorieux et al., 2016), and Parkinson's and Alzheimer's diseases (Bhattacharjee et al., 2016; Hamulakova et al., 2016). The oxidative stress can be relieved by the counteraction of defense system with ROS through neutralization with antioxidants (Wen et al., 2015). Functional dietary antioxidant ingredients originating from fermented foods play an important role in preventing occurrence of diseases associated with oxidative stress by directly inhibiting of lipid peroxidation, scavenging ROS, and regulating intestinal environment (Coskun Cevher et al., 2015). These dietary antioxidants mainly include bioactive peptides (Ohata et al., 2016), microbial enzymes, and metabolites (Mishra et al., 2015).

Kefir has been well known for its many health-benefiting activities, including antioxidative, antimicrobial, and anticarcinogenic activity (Ahmed et al., 2013). Exopolysaccharide (EPS) isolated from this traditional product were shown to possess antioxidant (Luang-In and Deeseenthum, 2016), anti-inflammatory, and angiogenic activities (Prado et al., 2016), as well as the ability to modulate metabolism of key microorganisms in gut microbiota (Serafini et al., 2014). The EPS from Weissella cibaria and Pediococcus pentosaceus were found to 
be highly resistant to gastric and intestinal digestions and capable of selective enhancement of beneficial gut bacteria, in particular Bifidobacteria (Hongpattarakere et al., 2012). The EPS produced by Lactobacillus plantarum DM5 showed a low digestibility by artificial gastric juice and inhibitory effect on the growth of nonprobiotic bacteria, such as Enterobacteriaceae (Das et al., 2014). These results indicated that EPS were similar to prebiotics and effective in regulation of gut microbiota in vitro (Serafini et al., 2014). As many oxidant-related diseases have been proven to relate to structure and metabolite change of microbiota, including colon cancer (Sears and Garrett, 2014), cardiovascular disease (Siti et al., 2015), diabetes (Karunakaran and Park, 2013), obesity (Nistala et al., 2014), and aging (Claesson et al., 2012), these findings suggest a possible mechanism of microbial EPS improving oxidative status of the host by regulating microbiota to selectively inhibit or eliminate microorganisms related to oxidative stress. Until now, the microbiota-regulatory effect of EPS produced by lactic acid bacteria (LAB) in vivo and their consequent influence on the oxidative status of host have not been studied. Considering the food-grade origin of EPS produced by LAB, determination of their microbiotaregulatory activity and health-beneficial functions on the host are important for their potential applications as functional ingredients and for further understanding the functional mechanism of LAB.

Previously, L. plantarum YW11 isolated from Tibetan kefir was shown to produce an EPS, which accounted for more than half amount of the polysaccharide secreted during kefir fermentation (Wang, 2015). This EPS had a molecular mass of $1.1 \times 10^{5} \mathrm{Da}$, consisting of glucose and galactose (molar ratio of 2.71:1) (Wang et al., 2015a). The present study was performed to examine the in vivo antioxidant effect of this EPS and determine its regulatory effect on the gut microbiota in correlation with the antioxidant status in an aging mouse model, in which oxidative stress was induced with D-galactose. Recovering the diversity and abundance of gut microbiota in the aging mice after administration of different doses of the EPS and the fermented milk with L. plantarum YW11 was investigated using microbial diversity analysis. A possible correlation of the gut microbiota change with the oxidative status of mice was studied using regression analysis.

\section{MATERIALS AND METHODS}

\section{Strains and Culture}

Lactobacillus plantarum YW11 was isolated from Tibetan kefir grains and kept in the dairy food processing laboratory of Beijing Technology and Business
University. Lactobacillus plantarum YW11 was cultured at $37^{\circ} \mathrm{C}$ for $18 \mathrm{~h}$ in skim milk medium prepared by reconstituting $10 \%$ skim milk powder (Fonterra, Auckland, New Zealand) in deionized water under nonshaking conditions. Fermented milk used in the in vivo experiment was prepared by fermenting the pasteurized $\left(85^{\circ} \mathrm{C}, 5 \mathrm{~min}\right) 10 \%$ (wt/wt) skim milk with only $L$. plantarum $\mathrm{YW} 11$ at $37^{\circ} \mathrm{C}$ for $18 \mathrm{~h}$, with the inoculation rate of $1 \%$ and viable count of $L$. plantarum YW11 at $8.41 \log \mathrm{cfu} / \mathrm{mL}$.

\section{Preparation of EPS}

Lactobacillus plantarum YW11 was cultured in $10 \mathrm{~L}$ of pasteurized $\left(85^{\circ} \mathrm{C}, 5 \mathrm{~min}\right)$ skim milk medium at $37^{\circ} \mathrm{C}$ for $18 \mathrm{~h}$. The EPS produced by the strain was then isolated and prepared using the method previously reported (Wang et al., 2015a). Briefly, after fermentation, $80 \%$ (wt/vol) trichloroacetic acid (TCA) was added to achieve the $4 \%$ (wt/vol) trichloroacetic acid concentration. The mixture was stirred at room temperature for $2 \mathrm{~h}$, and then centrifuged at $12,000 \times g$ for $30 \mathrm{~min}$ at $4^{\circ} \mathrm{C}$. The cold ethanol $\left(4^{\circ} \mathrm{C}\right)$ was added to the supernatant to achieve $70 \%$ concentration and then kept at $4^{\circ} \mathrm{C}$ overnight. The pellet of crude EPS was collected after centrifugation at $12,000 \times \mathrm{g}$ for $30 \mathrm{~min}$ at $4^{\circ} \mathrm{C}$. For purification, the EPS was dissolved in distilled $\mathrm{H}_{2} \mathrm{O}$ $(20 \mathrm{mg} / \mathrm{mL})$ and fractionated with a diethylaminoethyl cellulose column. Peak fractions containing EPS were lyophilized and fractionated by Sepharose CL-6B column (GE Healthcare, Pittsburgh, PA). The fraction of pure EPS was lyophilized into powder and stored at $-20^{\circ} \mathrm{C}$ for further use.

\section{In Vitro Antioxidant Activity}

Preparation of EPS Solution. The EPS solution was prepared by completely dissolving EPS in PBS $(\mathrm{pH}$ 7.2) to achieve concentrations of $0.25,0.5,1.0,2.0$, and $3.0 \mathrm{mg} / \mathrm{mL}$ for further tests. An ascorbic acid solution of the same concentrations was used as a positive control.

Determination of Hydroxyl Radical Scavenging Activity. The hydroxyl radical scavenging activity was examined using the method of Wang et al. (2009) with some modifications. Briefly, the reaction mixture containing $2.0 \mathrm{~mL}$ of $\mathrm{FeSO}_{4}(0.5 \mathrm{mM}), 1.0 \mathrm{~mL}$ of brilliant green $(0.435 \mathrm{~m} M), 1.5 \mathrm{~mL}$ of $\mathrm{H}_{2} \mathrm{O}_{2}(3.0 \%$, wt/vol), and $1.0 \mathrm{~mL}$ of EPS solution of different concentrations $(0.25,0.5,1.0,2.0$, and $3.0 \mathrm{mg} / \mathrm{mL})$ was incubated at $25^{\circ} \mathrm{C}$ for $20 \mathrm{~min}$, and the absorbance was measured at $624 \mathrm{~nm}$. The scavenging activity was calculated as scavenging activity $(\%)=\left[\left(A_{\text {sample }}-A_{\text {blank }}\right) /\left(A_{\text {control }}-\right.\right.$ $\left.\left.A_{\text {blank }}\right)\right] \times 100$, where $A_{\text {sample }}$ is the absorbance of the 
mixture containing EPS and Fenton solution, which was prepared by mixing previously mentioned solutions of $\mathrm{FeSO}_{4}$ and $\mathrm{H}_{2} \mathrm{O}_{2}, A_{\text {blank }}$ is the absorbance of mixture without EPS, and $A_{\text {control }}$ is the absorbance of mixture without EPS and Fenton solution.

Determination of 2,2-diphenyl-1-picrylhydrazyl Radical Scavenging Activity. The 2,2-diphenyl1-picrylhydrazyl (DPPH) radical scavenging capacity of EPS was determined using the method of Ye et al. (2012). Briefly, $1.0 \mathrm{~mL}$ of EPS solution of different concentrations $(0.25,0.5,1.0,2.0$, and $3.0 \mathrm{mg} / \mathrm{mL})$ was added to $2.0 \mathrm{~mL}$ of ethanolic DPPH radical solution $(0.05 \mathrm{mM})$. After thorough mixing, the mixture was incubated at $25^{\circ} \mathrm{C}$ for $30 \mathrm{~min}$ in a lucifugal cabinet. The mixture was centrifuged at $8,000 \times g$ for $10 \mathrm{~min}$ at $4^{\circ} \mathrm{C}$, and the absorbance of the supernatant was measured in triplicate at $517 \mathrm{~nm}$. The scavenging activity (\%) was calculated as $\left[1-\left(A_{\text {sample }}-A_{\text {blank }}\right) / A_{\text {control }}\right] \times 100$, where $A_{\text {sample }}$ is absorbance of the mixture containing EPS and DPPH solution; $A_{\text {control }}$ is absorbance of the mixture containing only deionized water and $\mathrm{DPPH}$ solution; and $A_{\text {blank }}$ is absorbance of mixture containing only ethanol and EPS.

Determination of Superoxide Anion Radical Scavenging Activity. The scavenging activity of superoxide radical was determined using the method of Giese et al. (2015). Briefly, $1.0 \mathrm{~mL}$ of EPS solution of different concentrations $(0.25,0.5,1.0,2.0$, and $3.0 \mathrm{mg} /$ $\mathrm{mL}$ ) or deionized water as a control was mixed with 3.0 $\mathrm{mL}$ of $0.05 M$ Tris-HCl buffer (pH 8.2) and incubated at $25^{\circ} \mathrm{C}$ for $10 \mathrm{~min}$. Then, $40 \mu \mathrm{L}$ of $45 \mathrm{mM}$ pyrogallol was added to the mixture and incubated for $5 \mathrm{~min}$. The absorbance of the resulting solution was measured in triplicate at $325 \mathrm{~nm}$. The scavenging ability (\%) was calculated as $\left[1-\left(A_{\text {sample }} / A_{\text {control }}\right)\right] \times 100$, where $A_{\text {sample }}$ is the absorbance of the sample containing EPS and $A_{\text {control }}$ is the absorbance of the sample without EPS.

Ferrous Ion Chelating Ability. Ferrous ion chelating activity was investigated using the method of Chen et al. (2015a). Briefly, the reaction mixture containing $0.2 \mathrm{~mL}$ of different concentrations of samples $(0.25,0.5,1.0,2.0$, and $3.0 \mathrm{mg} / \mathrm{mL}), \mathrm{FeCl}_{2}(0.1 \mathrm{~mL}, 2$ $\mathrm{m} M)$, and ferrozine $(0.4 \mathrm{~mL}, 5 \mathrm{mM})$ was shaken well and incubated for $10 \mathrm{~min}$ at room temperature. The absorbance of the mixture was measured at $562 \mathrm{~nm}$ against a blank (the same volume of PBS). Ethylene diamine tetraacetic acid was used as the standard positive control.

\section{Animal Experiments}

Animal Grouping and Treatment. The animal experiments in our study were performed at the animal facilities of a local hospital in Beijing, China, and conducted strictly according to the Provisions and General Recommendations of Chinese Experimental Animal Administration Legislation. After 1 wk of acclimatization, 48 male Institute of Cancer Research mice (8 wk old, $23-25 \mathrm{~g}$ of BW) were randomly divided into 6 groups ( 8 mice per group); 2 mice in each group were used as a backup. Daily treatments were performed according to Table 1 . The mice in the treatment groups were subcutaneously injected with $10 \mathrm{~mL}$ of $5 \%$ (wt/ wt) D-galactose solution per $\mathrm{kg}$ of $\mathrm{BW}$ per day to induce oxidative stress; the mice in the normal group were injected with $10 \mathrm{~mL}$ of $0.9 \%$ (wt/wt) normal saline solution per $\mathrm{kg}$ of BW per day by oral gavage. The mice in the aging group received $20 \mathrm{~mL}$ of $0.9 \%$ (wt/ wt) normal saline solution per $\mathrm{kg}$ of BW per day by oral gavage and served as a negative control. The mice in the vitamin $\mathrm{C}$ (VC) group received $20 \mathrm{~mL}$ of $1 \mathrm{mg} /$ $\mathrm{mL}$ ascorbic acid solution per $\mathrm{kg}$ of BW per day and served as a positive control. The mice in the low-dose (LD) group received $20 \mathrm{~mL}$ of $1 \mathrm{mg} / \mathrm{mL}$ EPS solution per kg of BW per day; the mice in the high-dose (HD) group received $20 \mathrm{~mL}$ of $2.5 \mathrm{mg} / \mathrm{mL}$ EPS solution per $\mathrm{kg}$ of BW per day; and the mice in the fermented milk (FM) group received $20 \mathrm{~mL}$ of fermented milk per $\mathrm{kg}$ of BW per day. The fermented milk contains $8.41 \log \mathrm{cfu} /$ $\mathrm{mL}$ of viable $L$. plantarum YW11 strains. The whole process lasted for $12 \mathrm{wk}$.

Detection of Antioxidant Activity in Serum. After the mice were anesthetized using diethyl ether (Sinopharm Chemical Reagent Co. Ltd., Beijing, Chi-

Table 1. Groups of experimental mice and their daily treatments ${ }^{1}$

\begin{tabular}{lll}
\hline Group & $\begin{array}{l}\text { Oral gavage } \\
(/ \mathrm{kg} \text { of BW/day) }]\end{array}$ & $\begin{array}{l}\text { Subcutaneous injection } \\
(/ \mathrm{kg} \text { of BW/day) }\end{array}$ \\
\hline Normal & $20 \mathrm{~mL}$ of NSL & $10 \mathrm{~mL}$ of NSL \\
Aging & $20 \mathrm{~mL}$ of NSL & $10 \mathrm{~mL}$ of $5 \%$ D-galactose solution \\
Ascorbic acid (VC) & $20 \mathrm{~mL}$ of $1 \mathrm{mg} / \mathrm{mL}$ ascorbic acid solution & $10 \mathrm{~mL}$ of $5 \%$ D-galactose solution \\
Low dose (LD) & $20 \mathrm{~mL}$ of $1 \mathrm{mg} / \mathrm{mL} \mathrm{EPS} \mathrm{solution}$ & $10 \mathrm{~mL}$ of $5 \%$ D-galactose solution \\
High dose (HD) & $20 \mathrm{~mL}$ of $2.5 \mathrm{mg} / \mathrm{mL}$ EPS solution & $10 \mathrm{~mL}$ of $5 \%$ D-galactose solution \\
Fermented milk (FM) & $20 \mathrm{~mL}$ of fermented milk & $10 \mathrm{~mL}$ of $5 \%$ D-galactose solution \\
\hline
\end{tabular}

${ }^{1} \mathrm{VC}=$ group of mice treated with vitamin $\mathrm{C}$; LD = group of mice treated with a low dose of exopolysaccharide (EPS); HD = group of mice treated with high dose of EPS; FM = group of mice treated with fermented milk; NSL $=0.9 \%$ normal saline. 
na), blood (about $2 \mathrm{~mL}$ ) was collected from the orbital vein plexus. The serum was prepared by centrifuging at $3,000 \times g$ for $15 \mathrm{~min}$ at $4^{\circ} \mathrm{C}$. Serum was stored stored at $-70^{\circ} \mathrm{C}$ for further analysis. Enzyme-linked immunosorbent assay kits (Nanjing Jiancheng co., Nanjing, China) were used to determine the malondialdehyde (MDA) level, and the activities of glutathione peroxidase (GSH-Px) activity, total antioxidant capacity (T-AOC), catalase (CAT), and superoxide dismutase (SOD) in the serum following the manufacturer's protocol (http://www.njjcbio.com/product.asp?cid=27). Briefly, the MDA level was measured by the 2-thiobarbituric acid method and expressed as nanomoles per milliliter in serum. The enzymatic activities of GSH$\mathrm{Px}, \mathrm{T}-\mathrm{AOC}, \mathrm{CAT}$, and SOD were determined using the methods of $\mathrm{GSH}-\mathrm{H}_{2} \mathrm{O}_{2}$ reaction system, ferric-reducing/ antioxidant power reaction system, $\mathrm{CAT}-\mathrm{H}_{2} \mathrm{O}_{2}$ reaction system, and xanthine oxidase-xanthine reaction system, respectively. The enzymatic activities were expressed as units per milliliter in serum.

Fecal DNA Extraction and Pyrosequencing. Genomic DNA was extracted from fecal samples by bead beating and using a 51504-QIAamp DNA Stool Mini Kit (Qiagen, Hilden, Germany). In brief, approximately $0.22 \mathrm{~g}$ of frozen feces were added to a 2 -mL Eppendorf tube containing $1 \mathrm{~mL}$ of InhibitEX buffer of the kit and $0.3 \mathrm{~g}$ of glass beads $(0.1 \mathrm{~mm}$, Biospec Products Inc., Bartlesville, OK). After sufficient homogenization by vortexing for $1 \mathrm{~min}$, bead beating was performed for $1 \mathrm{~min}$ at full speed. Bacterial DNA was extracted using proteinase $\mathrm{K}$ treatment and subsequent purification following the manufacturer's protocol (https:// www.qiagen.com/cn/shop/sample-technologies/dna/ genomic-dna/qiaamp-dna-stool-mini-kit/\#resources). The extracted DNA from each sample was used as the template to amplify a 250 to $300 \mathrm{bp}$ fragment covering the V4 region of $16 \mathrm{~S}$ rRNA genes. Sequences of the fragment were obtained by paired-end sequencing using MiSeq PE300 (Illumina Inc., San Diego, CA). Polymerase chain reaction amplification, pyrosequencing of PCR amplicons, and quality control of raw data were performed as described previously (Wang et al., 2012).

\section{Bioinformatics and Multivariate Statistics}

Pyrosequencing sequences of high quality (excluding truncated sequences below an average quality of 20 over a 25-bp sliding window, sequences with trimmed reads having less than $75 \%$ of their original length, and sequences with reads contaminated by adapter, ambiguous bases and reads with 10 consecutive same base) were compared and clustered using cluster database at high identity with tolerance with $99 \%$ or higher similarity. The longest sequence in each cluster was aligned against the Greengenes database (DeSantis et al., 2006) to construct a neighbor-joining tree. Operational taxonomic units (OTU) with higher than 97\% similarity were delineated using the method of Schloss and Handelsman (2005), in which a distancebased OTU and richness (DOTUR) program was used and sequences were assigned to OTU according to their distance level in neighbor algorithm. The coverage of OTU was calculated as coverage $=1-n 1 / N$, where $n 1$ is the number of OTU containing only 1 sequence and $N$ is the numbers of OTU in the sample. The principal coordinate analysis (PCoA) was applied to determine the differences in OTU composition of different groups and key factors responsible for the difference using a relative abundance value. The distance of samples in the PCoA plot stood for the similarity of species composition between the samples. The software used in this step was package ade4 of $\mathrm{R}$ software (v3.1.1; https:// www.r-project.org/).

A redundancy analysis (RDA) was completed with CANOCO (Microcomputer Power, Ithaca, NY) according to the software manual (Braak and Smilauer, 2002). Briefly, species and environmental data were input into CANOCO software. In the method-selection inspection, the lengths of gradient (2.77) in the detrended correspondence analysis was lower than 3.0, suggesting that the method of RDA was more suitable for data analysis than for canonical correspondence analysis. Parameters of RDA were set as "Focus scaling on" = "Symmetric," "Species scores" = "Divide by standard deviation," "Centering and standardization samples" = "none," "center by species." The significance of RDA analysis was calculated using the Monte Carlo permutation procedure with 499 random permutations. The OTU with at least $10 \%$ of variability in their values explained by the first axis in RDA were used in further analysis as key OTU. The heat map of key OTU was plotted according to the method described by PerezLlamas and Lopez-Bigas (2011). Briefly, the key OTU were arranged according to their neighbor-joining positions, and the relative abundance data of the key OTU were normalized and log-transformed before building correspondence to the color squares using the software of $\mathrm{MeV}$ (Dana-Farber Cancer Institute, Boston, MA).

Possible correlation of gut microbiota structure with the oxidative status of mice was predicted using the partial least square regression (PLS) model. The performance of regression model was examined using leave-one-out cross-validation (Wold et al., 2001) and Pearson correlation coefficient and $P$-value between predicted and detected values. The analysis was performed using XL stat2015 software (Addinsoft, New York, NY). 


\section{Nitrogen Oxides Determination}

The concentration of nitrogen oxides $\left(\mathbf{N O}_{\mathbf{x}}\right)$ in the feces was determined using a Griess reaction (Green et al., 1982). Specifically, $0.5 \mathrm{~mL}$ of the supernatant of fecal samples was prepared by the homogenization of feces $(0.2 \mathrm{~g})$ with $1.0 \mathrm{~mL}$ of PBS (pH 7.4) and centrifugation at $3,000 \times g$ for 5 min at $4^{\circ} \mathrm{C}$. The supernatant was mixed with $0.25 \mathrm{~mL}$ of $0.3 \mathrm{M} \mathrm{NaOH}$ and incubated at $25^{\circ} \mathrm{C}$ for $5 \mathrm{~min} ; 0.25 \mathrm{~mL}$ of $10 \%$ (wt/vol) $\mathrm{ZnSO}_{4}$ was then added and centrifuged at $12,000 \times g$ for $10 \mathrm{~min}$ at $4^{\circ} \mathrm{C}$ for the elimination of protein. The nitrate content in supernatant was determined using the spectrophotometric method before reduction into nitrite using $\mathrm{VaCI}_{3}$. The standard curve was plotted with sodium nitrite solution of $0,5,10,20,50$, and $100 \mu \mathrm{mol} / \mathrm{L}$.

\section{Short-Chain Fatty Acids Determination}

Fecal samples were homogenized by mixing with 0.9 $\mathrm{mL}$ of $0.01 M$ PBS. The mixture was centrifuged at $8,000 \times g$ for $10 \mathrm{~min}$ at $4^{\circ} \mathrm{C}$. The supernatant was mixed with one-sixth volume of $7 \mathrm{MH}_{2} \mathrm{SO}_{4}$ and extracted with $1 \mathrm{~mL}$ of ethyl ether by vibration for $5 \mathrm{~min}$. The concentrations of acetic, propionic, butyric, and isobutyric acid were determined using the GC method reported by (Wu et al., 2016).

\section{Statistical Analysis}

All chemical measurements were done in triplicate samples on duplicate trials and data were presented as means \pm standard deviation of means. Statistically significant differences were determined by one-way ANOVA followed by Tukey's tests in SPSS 22.0 software (IBM Corp., Armonk, NY).

\section{RESULTS AND DISCUSSION}

\section{In Vitro Antioxidant Activity}

Hydroxyl, DPPH, and superoxide radicals have been widely accepted as models for evaluating ROS-related antioxidant activity (Wu and Huang, 2017). The scavenging capacities of the EPS produced by L. plantarum YW11 against these 3 ROS were examined using ascorbic acid as a positive control. Figure $1 \mathrm{~A}-\mathrm{C}$ shows that the EPS at all concentrations $(0.25,0.5,1.0,2.0$, and $3.0 \mathrm{mg} / \mathrm{mL}$ ) exhibited clear scavenging activities against the radicals in a concentration-dependent manner, and the corresponding range of scavenging activity was 15.07 to $75.10 \%$ on hydroxyl radical, 3.42 to
$62.71 \%$ on superoxide anion, and 4.91 to $35.11 \%$ on DPPH. A slight increase in scavenging capacity with the concentration of EPS was observed at EPS concentrations higher than $2.0 \mathrm{mg} / \mathrm{mL}$. This might be due to the decreased solubility of EPS, as indicated by the laser light scattering test showing the increased particle size of polysaccharide at the concentration higher than $2.0 \mathrm{mg} / \mathrm{mL}$ (data not shown). The half maximal inhibitory concentration values of EPS on hydroxyl radicals, superoxide anion, and DPPH were 1.22, 1.54, and 0.63 $\mathrm{mg} / \mathrm{mL}$, corresponding to the activity of ascorbic acid at $0.47,0.71$, and $0.61 \mathrm{mg} / \mathrm{mL}$, respectively. The half maximal inhibitory concentration values concentration of EPS on the ferrous ion was $1.07 \mathrm{mg} / \mathrm{mL}$, with that of EDTA at $0.29 \mathrm{mg} / \mathrm{mL}$. Their maximal scavenging rates were reached at the concentration of $3.0 \mathrm{mg} / \mathrm{mL}$, being $75.10 \%$ for hydroxyl radical and $62.71 \%$ for superoxide anion. These maximal scavenging rates accounted for 88.23 and $76.54 \%$ of the capacity of the positive control (ascorbic acid), respectively. Among ROS, hydroxyl and superoxide radicals were strong oxidative radicals that could severely injure biomolecules, leading to aging, cancer, and declined physiological function (Li et al., 2014). Superoxide radicals were precursors to lipid peroxidants that reacted with cell membrane to cause tissue damage (Li et al., 2014). Figure 1B indicates a relatively low scavenging capacity of EPS against DPPH (35.11\%), which was $43.75 \%$ of that for ascorbic acid. A similar low scavenging capacity of microbial EPS against DPPH was reported earlier ( $\mathrm{Li}$ and Shah, 2014; Ye et al., 2016); however, a mixture of the EPS from different microorganisms demonstrated better DPPH-scavenging capacity (Chen et al., 2015b) and the reason was unclear.

Ferrous ion has been shown to be a generator of hydroxyl radicals via Haber-Weiss reaction $\mathrm{Fe}^{2+}+\mathrm{H}_{2} \mathrm{O}_{2} \rightarrow$ $\mathrm{Fe}^{3+}+\mathrm{OH}^{-}+\cdot \mathrm{OH}$ (Panat et al., 2016). Chelating ferrous ion was considered as a secondary mechanism to estimate the antioxidant activity of compound, besides directly scavenging hydroxyl radicals (Santos et al., 2017). Figure 1D shows that the ferrous chelating rate of the EPS from L. plantarum YW11 increased along with the concentration, and the highest chelating rate $(41.09 \%)$ achieved was close to half of the capacity of EDTA (86.25\%). The metal ion-chelating ability of LAB has been widely reported; some strains were studied for application in the removal of heavy metals in a polluted environment (Yin et al., 2016). However, the ion-chelating ability of EPS produced by LAB is not well studied. Some EPS exhibited no metal ionchelating capacity (Wang et al., 2015b), whereas some showed a strong chelating effect (Polak-Berecka et al., 2014); this difference needs to be further studied. 


\section{Antioxidant Activity of the EPS Produced by FM in the Aging Mice Model}

An aging mouse model was applied to further analyze the antioxidant activity of EPS, which was induced by a subcutaneous injection of $500 \mathrm{mg} / \mathrm{kg}$ per day of $5 \%$ D-galactose solution. The effectiveness of this model was proved in the previous reports (Prakash and $\mathrm{Ku}-$ mar, 2013; Yu et al., 2016). As shown in Table 1, the mice with oxidative stress were fed LD (20 mg/kg per day) and HD (50 mg/kg per day) of EPS produced by L. plantarum YW11, and the FM with L. plantarum YW11 as therapy groups. The mice fed VC $(20 \mathrm{mg} /$ $\mathrm{kg}$ per day) were used as a positive control, and the D-galactose-treated mice as a negative control.
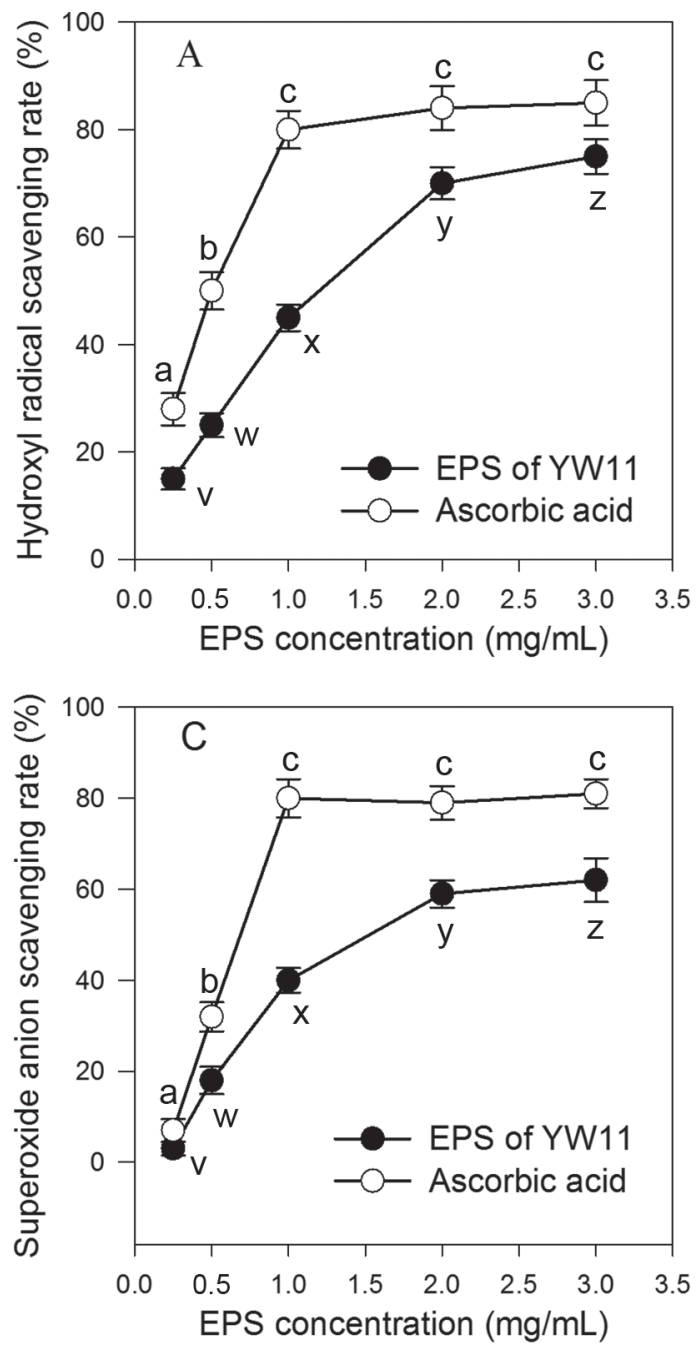

As shown in Figure 2, the mice treated only with D-galactose showed a severe increase in MDA activity and a decrease in GSH-Px, SOD, CAT, and T-AOC activities in serum compared with the normal group, indicating an oxidation in mice (Ho et al., 2003). The MDA level in the serum of D-galactose-treated mice was $11.69 \mathrm{mmol} / \mathrm{mL}(P<0.05)$. The MDA levels of HD group $(5.89 \mathrm{mmol} / \mathrm{mL} ; P<0.05)$ and $\mathrm{FM}$ group $(6.62 \mathrm{mmol} / \mathrm{mL} ; P<0.05)$ decreased near that of $\mathrm{VC}$ group $(5.66 \mathrm{mmol} / \mathrm{mL} ; P<0.05)$ and normal group mice $(5.24 \mathrm{mmol} / \mathrm{mL} ; P<0.05)$, indicating an effective blocking of lipid oxidation in serum by EPS and fermented milk with L. plantarum YW11. Similarly, the EPS from Bifidobacteria could lower the MDA level of mice to a normal level (Xu et al., 2011).
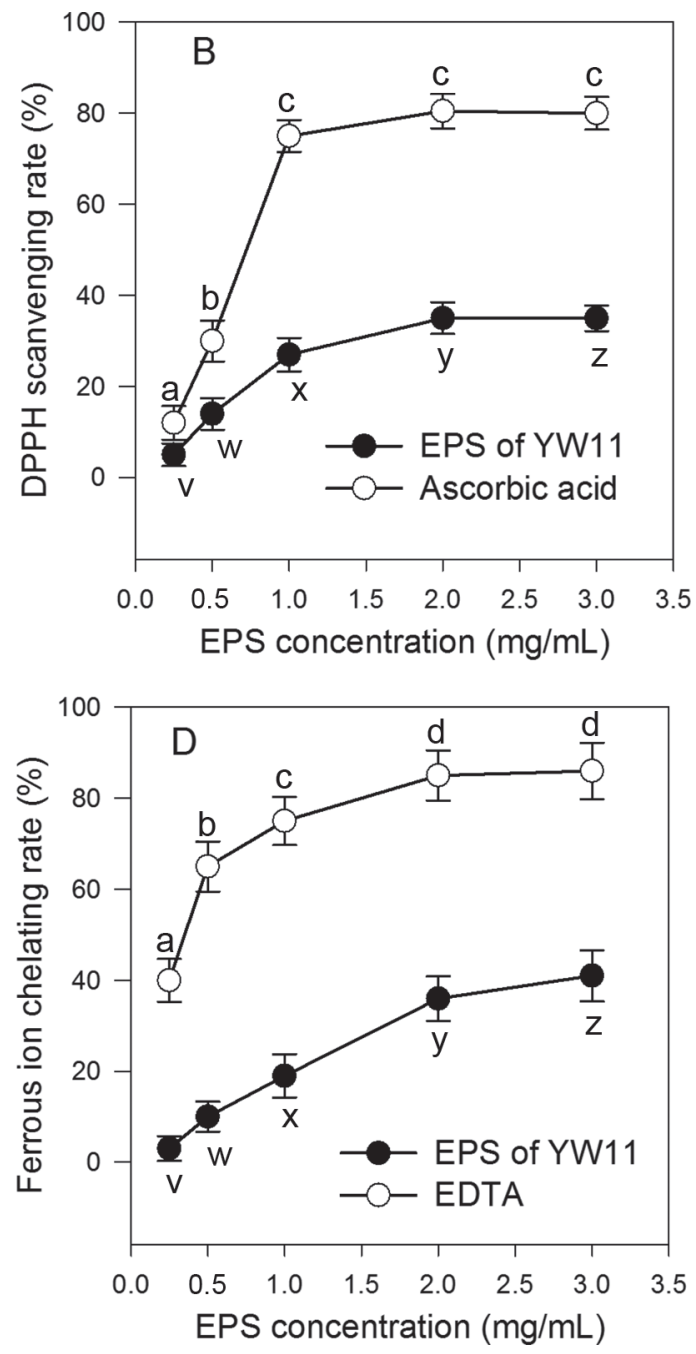

Figure 1. Scavenging capacities of the exopolysaccharide (EPS) produced by Lactobacillus plantarum YW11 on hydroxyl radicals (A), 2, 2-diphenyl-1-picrylhydrazyl (DPPH) radicals (B), and superoxide anion (C), as well as Fe ${ }^{2+}$ chelating ability of EPS (D). Different letters (a-d; v-z) denote significantly different values $(P<0.05)$ in scavenging or chelating rates within a treatment at different EPS concentrations and between treatments at a given EPS concentration. Points represent the mean values of scavenging or chelating rate, and the error bars represent the SD. 

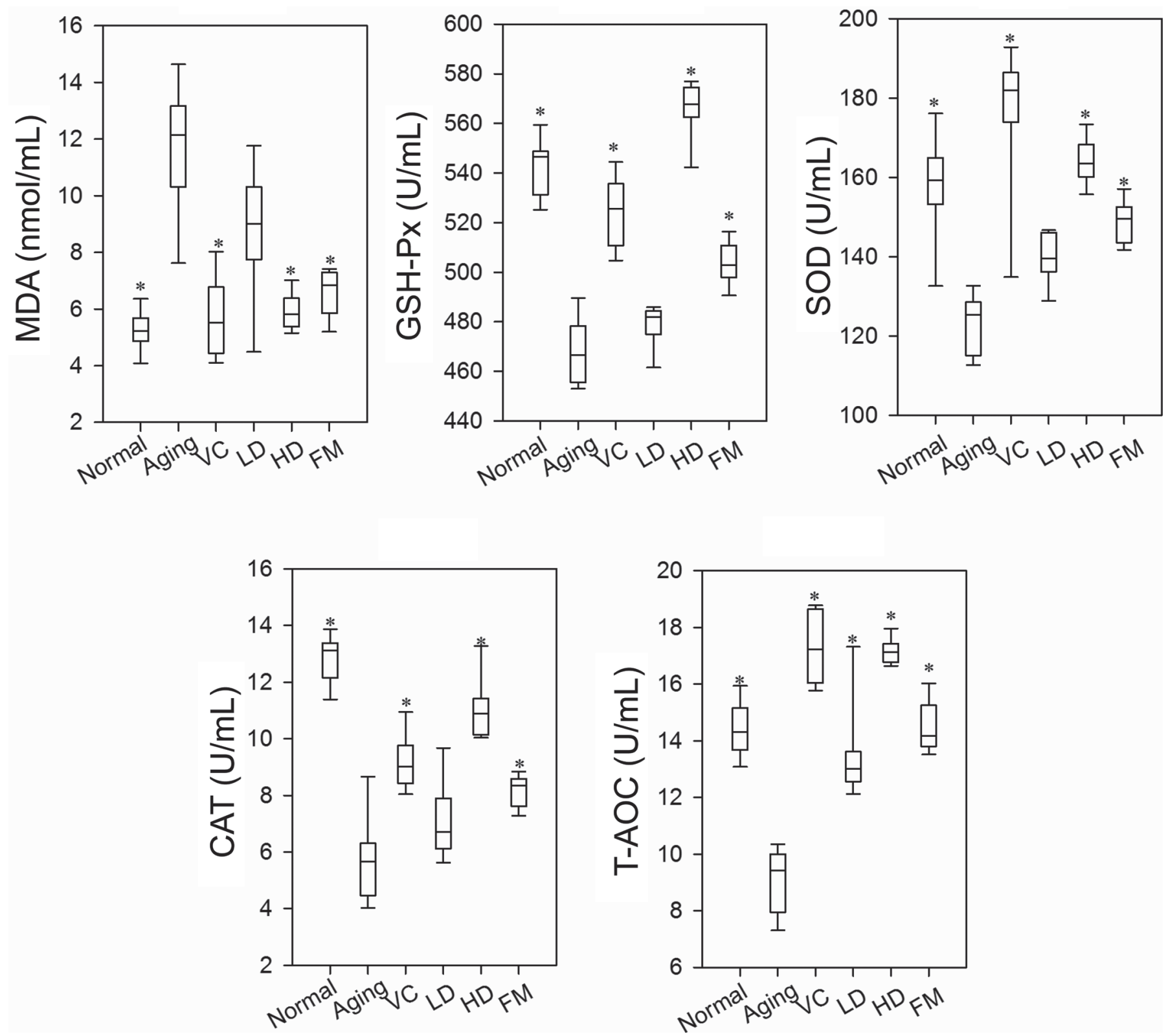

Figure 2. Effects of different treatments on the malondialdehyde (MDA) level, glutathione peroxidase (GSH-Px) activity, superoxide dismutase (SOD) and catalase (CAT) levels, and total antioxidant capacity (T-AOC) in the serum of mice, which were determined using ELISA. The experimental animal groups used were normal, aging (treated with D-galactose to induce oxidative stress), vitamin C (VC; treated with ascorbic acid) low dose [LD; treated with $20 \mathrm{mg} / \mathrm{kg}$ per day of exopolysaccharide (EPS) produced by Lactobacillus plantarum YW11], high dose (HD; treated with a $50 \mathrm{mg} / \mathrm{kg}$ per day of EPS), and fermented milk (FM; treated with milk fermented with Lactobacillus plantarum YW11). An asterisk $(*)$ represents a significant difference from that in the aging group $(P<0.05)$. The box plot represents median, inter-quartile range, minimum and maximum values of data.

Among the 3 treatment groups (LD, HD, and FM), HD group had the highest serum activities of GSH-Px, SOD, CAT, and T-AOC $(P<0.05)$. Compared with the D-galactose-treated mice, the activities of these enzymes in the HD group increased by $21.55,33.14$, 61.09 , and $38.18 \%$, respectively; the CAT activities were higher than those in the VC group $(P<0.05)$. This indicated that the EPS produced by L. plantarum
YW11 attenuated the decrease in the antioxidant enzymes in blood serum, stimulating a consequent recovery toward normality.

Although the HD of EPS from L. plantarum YW11 significantly influenced the level of antioxidant enzymes in vivo, MDA, GSH-Px, SOD, and CAT activities of the LD group were not significantly different from those of aging mice $(P>0.05)$. The enzyme activities (GSH- 
$\mathrm{Px}, \mathrm{SOD}, \mathrm{CAT}$, and T-AOC) in mice serum treated by FM containing 1/10 amount of EPS (90-100 mg/L), corresponding to the LD group, increased by 7.65 , $20.80,43.31$, and $31.05 \%(P<0.05)$, respectively. The insignificant effect of low-dose EPS in vivo indicated a dose-dependent antioxidant activity of EPS. The controversial results of the LD and FM groups might be due to the presence of other antioxidant components in fermented milk. Many antioxidant ingredients were reported in fermented milk, including peptides (Sah et al., 2014), fatty acids (Kusche et al., 2015), riboflavin (Thakur et al., 2016), microorganisms (Gan et al., 2014), and enzymes (Kumar et al., 2010), which could increase the antioxidant activity of fermented milk by 175 to $358 \%$ (Gagnon et al., 2015).

The antioxidant activities of $L$. plantarum strains, both in vitro and in vivo (Amaretti et al., 2013; Kumar et al., 2012; Li et al., 2012), and the in vitro antioxidant activity of their EPS have been reported (Arun et al., 2017; Zhang et al., 2013), but the in vivo antioxidant activities of these EPS and their effective doses are still not clear. In our study, the EPS produced by L. plantarum YW11 was found to effectively improve the index of oxidative status in an aging mouse model in a dosedependent manner. Other EPS isolated from kefir was shown to be fermented by the gut microbiota and thus influence its structure (Serafini et al., 2014). As the gut microbiota has been proven to be correlated with the oxidative status of the host (Jones et al., 2012; Clark et al., 2015), the influence of EPS on the gut microbiota and consequent effect on the oxidative status of aging mice were studied.

\section{Gut Microbiota Changes in Mice Treated with EPS and Fermented Milk}

The gut microbiota changes in mice in response to different treatments were studied using a high-throughput DNA sequencing technique (Wang et al., 2012).

Diversity Change Analysis. A total of 171,587 qualified pyrosequencing reads were obtained from 6 group of samples. After eliminating sequences without contagious neighbors (bacteria with a very similar $16 \mathrm{~S}$ sequence to the submitted sequence, as defined by the default criteria in the database of Greengenes), reads were delineated into 445 OTU on the $97 \%$ similarity level. Values of range $(0.977-0.996 ; P<0.01)$ and median $(0.982 ; P<0.01)$ coverage of OTU showed that the sequencing depth was sufficient. The diversity change in intestinal microbiota of different groups was examined using these OTU.

Observed species index, Shannon-Wiener index (SWI), and Simpson index (Strong, 2016) were calculated to measure the $\alpha$ diversity. As shown in Figure
$3 \mathrm{~A}$, the observed species index (285 OTU) of the aging mice group was the lowest among the 6 groups $(P$ $<0.05$ ); it lost $18.57 \%$ phylotypes of gut microbiota compared with the normal group (350 OTU). This indicated that the oxidative status of D-galactose-induced aging mice changed the phylotype richness of gut microbiota. The HD group (337 OTU) showed the least difference in phylotype richness $(P<0.05)$, suggesting a better recovery effect of HD EPS treatment on the phylotype richness of intestinal microbiota in aging mice. Observed species indexes of the VC, LD, and FM groups were 320,292 , and 293 OTU, respectively, with no significant difference $(P>0.05)$ between the LD and FM groups.

The SWI and Simpson index were also assessed to investigate the phylotypes evenness of gut microbiota (Brackney et al., 2015). The evenness in the gut microbiota of the HD group (SWI $=4.27 ; P<0.05)$ was the highest, and that of the aging group (SWI $=2.86$; $P<0.05)$ was the poorest. The evenness of the normal group $(\mathrm{SWI}=3.62), \mathrm{VC}(\mathrm{SWI}=3.73), \mathrm{LD}(\mathrm{SWI}=$ 3.86 ), and FM (SWI = 3.85) groups was also better than that of the aging group. These results indicated that, although fermented milk and low-dose EPS treatment exerted a weak effect on recovering the phylotype richness of aging mice compared with $\mathrm{HD}$ and $\mathrm{VC}$ treatments $(P<0.05)$, they could affect the diversity of microbiota by changing the phylotype evenness.

For direct perception of the difference between each treatment on microbiota, reduced analyzing dimension of unweighted UniFrac data were employed using PCoA (Dominguez-Bello et al., 2010). The horizontal axis (PCoA1) in Figure 3B explains $32.31 \%$ of total variance, and the vertical axis (PCoA2) explains $23.07 \%$. The distance of symbols represents the degree of difference between groups they stand for. The symbol of the aging mice group shows the farthest distance to the symbol of the normal group along the PCoA2 axis. The symbols of EPS (LD and HD groups) are located in the opposite direction, indicating that the influence of EPS on microbiota was opposite that of D-galactose (aging mice group). The distances between symbols representing $\mathrm{HD}$ and $\mathrm{VC}$ are shorter than others to the symbol of normal mice, showing that the recovery effects of the 2 groups on microbiota diversity were better than those of other groups. The symbol of the FM group has the longest distance to the symbols of the other groups, indicating that the milk fermented by L. plantarum YW11 influenced gut microbiota in a unique pattern. The analysis of unweighted UniFrac diversity distance (Figure 3C) was confirmed by results of PCoA.

Current conclusions about the relationship between gut microbiota diversity and oxidative status in aging hosts are based on specific species of strains, such as 

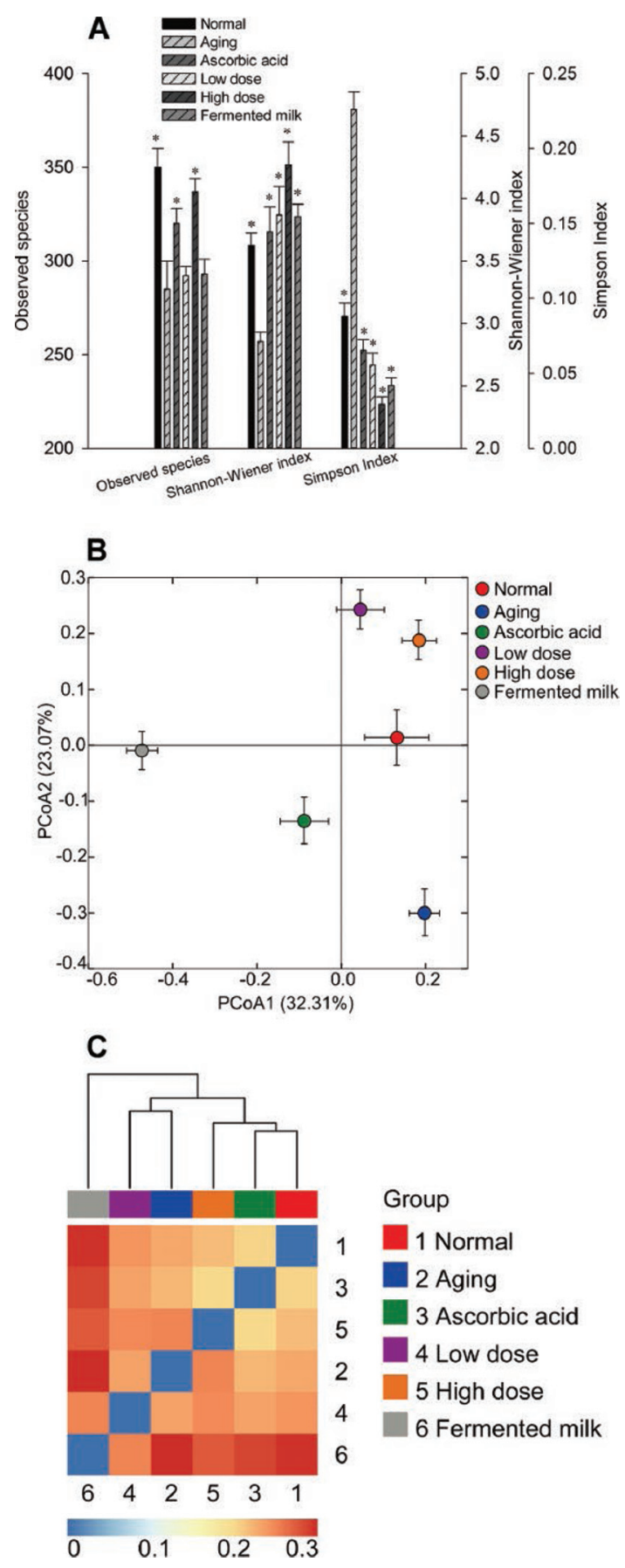

Figure 3. Diversity changes in microbiota. (A) Observed-species index, Shannon-Wiener index, and Simpson index, with values expressed as means \pm SD. An asterisk $(*)$ represents a significant difference compared with D-galactose-treated mice $(P<0.05)$. Principal coordinate analysis (PcoA; B) of the diversity distance and unweighted UniFrac diversity distance heat map $(\mathrm{C})$ were used to exhibit $\beta$ diversity distance distribution and the difference between groups of normal and aging mice, and mice treated with ascorbic acid, a low dose of exopolysaccharide (EPS) produced by Lactobacillus plantarum YW11, a high dose of EPS, and milk fermented by L. plantarum YW11. Each point represents the mean principal component scores of all rats in a group. Samples in heat map (C) are also clustered according to their similarity. Color version available online.
Helicobacter pylori with lipid peroxidation (Davì et al., 2005 ), or interactions of microbiota with the aging process in insect models (Wong et al., 2011; Cabreiro and Gems, 2013). In our study, a D-galactose-induced aging mouse model was employed and treatments with ascorbic acid, EPS, and fermented milk were found to affect the diversity recovery, abundance, and evenness of gut microbiota to different extents. Microbiota variations in response to different treatments were analyzed at the family and genus levels to further study the influence of different treatments on gut microbiota.

Key Phylotypes of the Gut Microbiota Responding to EPS and Other Treatments. A redundancy analysis (Figure 4) was employed to analyze the pyrosequencing data of these samples for identifying key phylotypes of the gut microbiota responding to different treatments (D-galactose, VC, EPS, and FM). Overall, 232 key OTU were identified with at least $10 \%$ of their variability explained by the horizontal axis. The corresponding families of the OTU (Figure 5 and Supplemental Table S1; https://doi.org/10.3168/ jds.2016-12480) were mainly Lachnospiraceae (51 OTU), S24-7 (39 OTU), Ruminococcaceae (34 OTU), Rikenellaceae (10 OTU), Desulfovibrionaceae (7 OTU), Bacteroidaceae (6 OTU), Paraprevotellaceae (4 OTU), Prevotellaceae (4 OTU), Lactobacillaceae (4 OTU), Helicobacteraceae (3 OTU), Anaeroplasmataceae (3 OTU), Odoribacteraceae (3 OTU), Porphyromonadaceae (3 OTU), Alcaligenaceae (3 OTU), Clostridiaceae (3 OTU), and Erysipelotrichaceae (3 OTU). A total of 152 key OTU were decreased or eliminated in mice treated with D-galactose compared with the normal group. After the aging mice were treated with VC, LD EPS, HD EPS, and FM, the key phylotypes increased by $19,16,46$, and 29 OTU, respectively.

The horizontal axis in Figure 4 explains 29.99\% of the total variability, and the vertical axis explains $19.40 \%$ of the total variability. The effects of all treatments on the gut microbiota were significant, as tested by the Monte Carlo permutation procedure $(P=0.016)$. The symbols representing the HD and normal groups are located in the first quadrant, whereas the symbols of the LD and aging groups of mice are in the opposite quadrant. Key OTU decreased in aging mice were recovered by $59.87 \%$ after the HD EPS treatment. The samples treated with VC and FM were distributed in the second and fourth quadrants, respectively, suggesting that their effect on the aging mice was different and also differed from that of normal mice.

The analysis at the genus level showed that OTU belonging to Flexispira were significantly enriched in the D-galactose group $(79.99 \% ; P<0.0001)$, whereas they were significantly lowered in the LD $(8.77 \%)$, HD (2.66\%), and FM (13.14\%) groups. Flexispira has been 


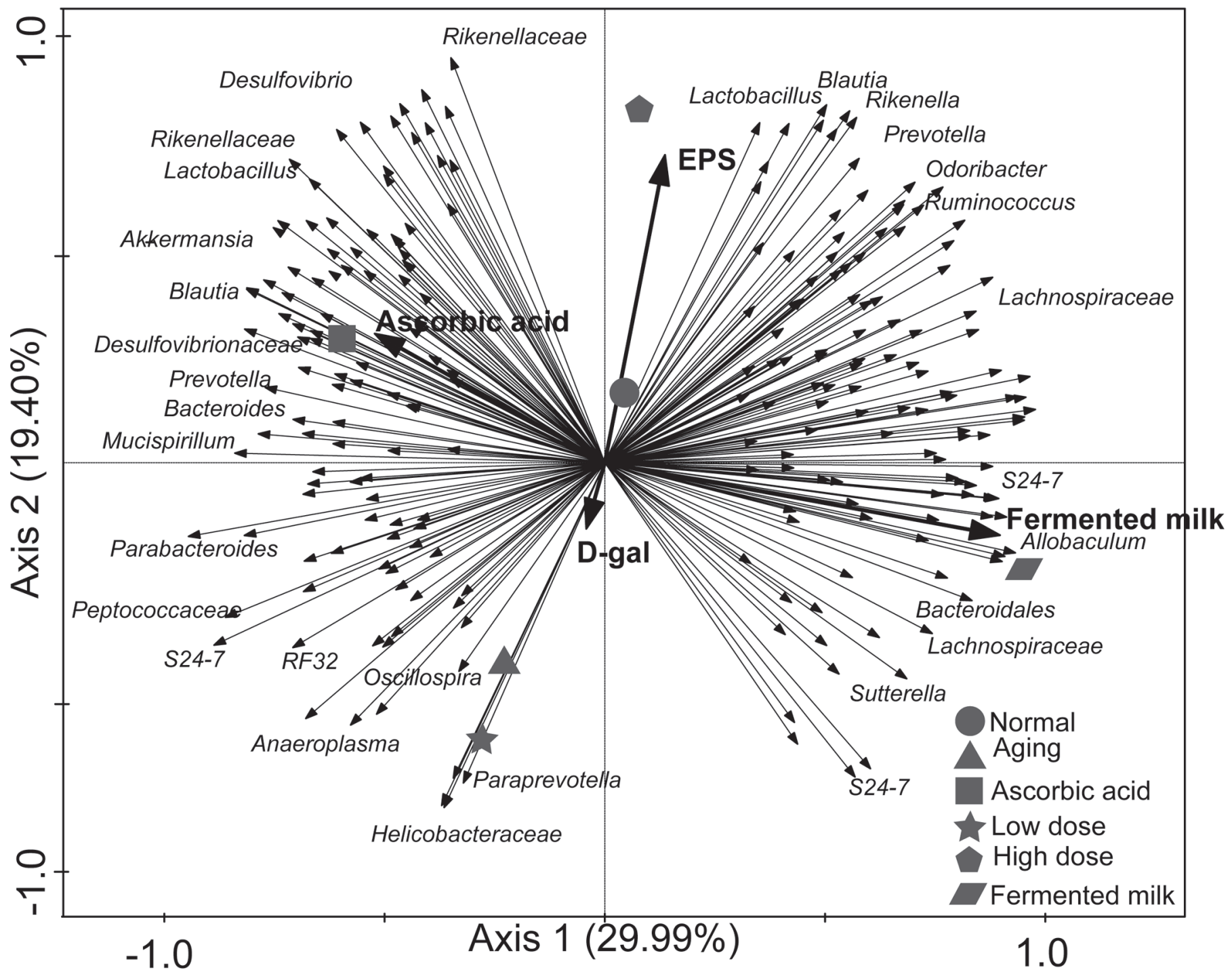

Figure 4. Distance triplot of the redundancy analysis of gut microbiota. Environmental variables [D-galactose (gal), ascorbic acid, exopolysaccharide (EPS), and fermented milk] are indicated by gray (red) thick arrows. Samples are represented by filled circles, including normal group, aging group, and groups treated by ascorbic acid, a low dose of EPS, a high dose of EPS, and milk fermented by Lactobacillus plantarum YW11. Key operational taxonomic units (OTU, 232 pieces) identified by the analysis are represented by thin black arrows. OTU better fitting to species are labeled with genus or family name. S24-7 and RF32 are unidentified families with unculturable characteristics and less similarity of their 16S rDNA sequences to any known families. P-value (0.016) was obtained by Monte Carlo permutation procedure.

reported to be recurrent in humans with inflammatory diseases (Gerrard et al., 2001), chronic diarrhea (Archer et al., 1988), gastrointestinal inflammation, or ulcer (Graham et al., 2007). The significant increase in richness of this genus in aging mice suggested that it might be related to the oxidative status of aging mice. The OTU belonging to Blautia (36.5-fold, $P=0.022$ ) and Prevotella (12.87-fold, $P=0.017$ ) were markedly enriched by VC and HD of EPS; OTU belonging to $B u$ tyricicoccus (9.5-fold, $P=0.033$ ) significantly enriched by HD of EPS and FM; OTU belonging to Allobaculum enriched by FM (Figure 4 and Supplemental Table S2; https://doi.org/10.3168/jds.2016-12480). Other OTU with relative abundance enriched by the HD of EPS, compared with D-galactose group, included AF12 (1 OTU), Anaeroplasma (1 OTU), Bacteroides (6 OTU), Bilophila (1 OTU), Clostridium (4 OTU), Dehalobacterium (2 OTU), Desulfovibrio (2 OTU), Mucispirillum (1 OTU), Odoribacter (3 OTU), Prevotella (7 OTU), Rikenella (2 OTU), Ruminococcus (9 OTU), Lactobacillus (4 OTU), and Oscillospira (19 OTU). Previously, Bacteroides, Ruminococcus, and Prevotella were reported to be the dominant genera in the mammalian intestinal tract. Arumugam et al. (2011) classified the gut 


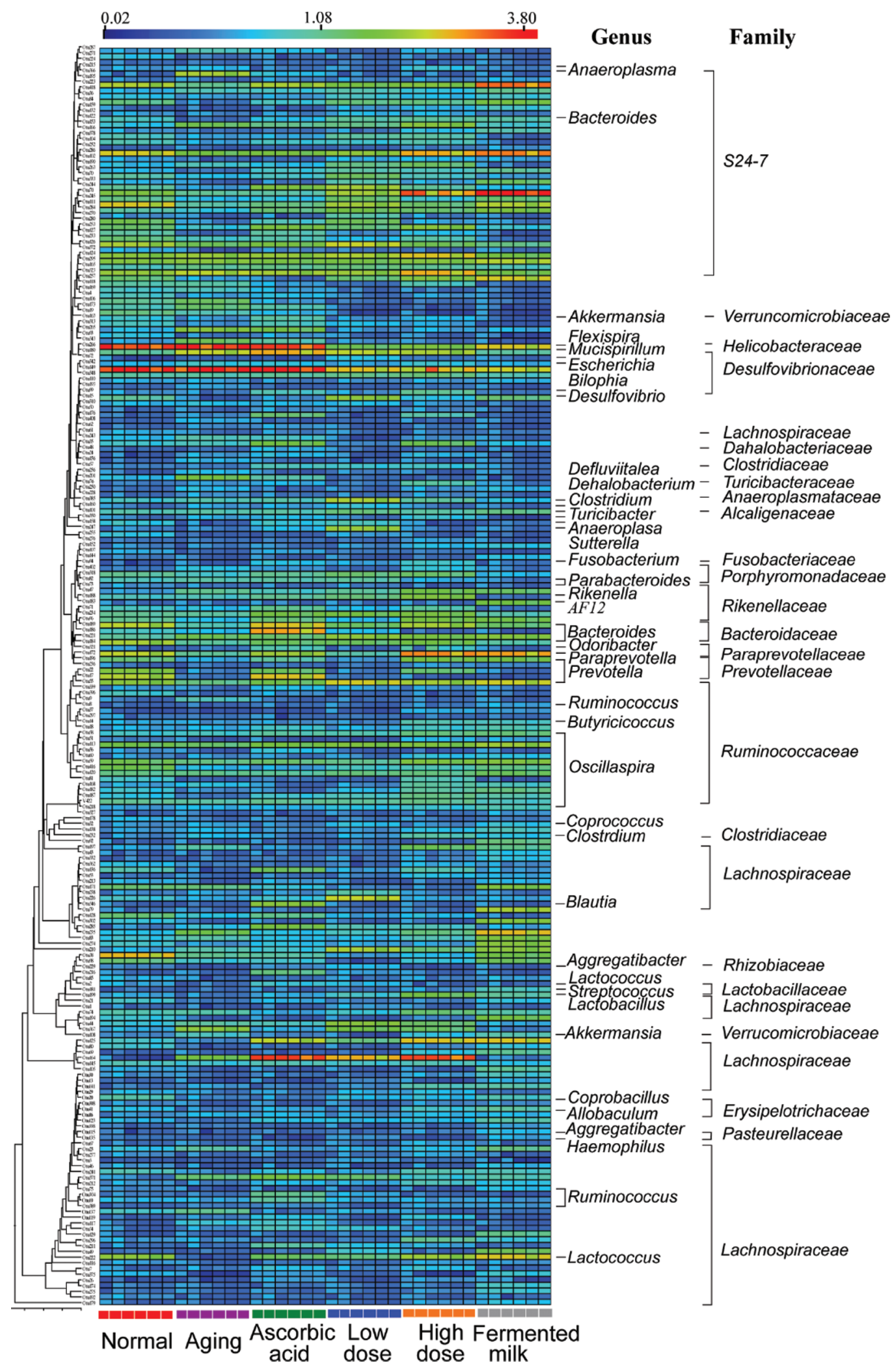

Figure 5. Heat map of 232 key operational taxonomic units (OTU) identified by redundancy analysis corresponding to different treatments. The relative abundance of OTU was taken after normalization and log-transformation; OTU were arranged by their sequence order in the neighbor-joining tree. The genus and family of the OTU are listed on the right. S24-7 and AF12 are the unidentified family and genus, respectively, with unculturable characteristics and less similarity of their 16S rDNA sequences to any known families or genera. Color version available online. 
microbiota of Europeans into 3 enterotypes based on the relative abundance of these 3 genera. Whether such a classification of gut microbiota is suitable for mice needs further study, although the abundance of these 3 genera increased in aging mice treated with HD EPS in the current study. Oscillospira and Bilophila belong to Firmicutes. Oscillospira is a dominant genus in the gut microbiota of ruminants; it is also present in the human intestinal tract. A previous report indicated that Oscillospira strains specialized in fermenting complex materials of low digestibility (Tims et al., 2013). This characteristic of Oscillospira explained why its abundance selectively increased with EPS treatment in our study. Bilophila is considered to be a disease-associated genus, with a causal relationship to colorectal carcinogenesis (Andersen and Vogel, 2014). The abundance of Bilophila in the gut of mice fed FM changed insignificantly $(P=0.67$, Supplemental Table S2), but increased significantly $(P=0.0061$, Supplemental Table S2) in mice fed with HD EPS in the current study; how EPS specifically increased the growth of Bilophila in mice gut was unclear. The EPS produced by some bacteria might be used as the energy source for their growth (Pham et al., 2000). The abundance of Lactobacillus in HD group was $86.44 \%$ that of the normal group, and higher than that of the FM group $(74.57 \%)$ in which mice were fed fermented milk containing $L$. plantarum YW11. This indicated that EPS might function as a prebiotic to effectively promote the growth of lactobacilli, increasing health-benefiting microorganisms in the gut microbiota.

Microbiota modulatory function was considered as one of the most important mechanisms for probiotics exerting their health-benefiting effects on the host (Kristensen et al., 2016). Exopolysaccharides, as a key metabolite of some probiotics, might play an important role in modulating gut microbiota, as some of them were found to be used by other probiotics (Bifidobacterium; Hongpattarakere et al., 2012) and inhibit the growth of nonprobiotic bacteria (Enterobacteriaceae) in vitro (Das et al., 2014). In our study, the EPS produced by L. plantarum YW11 was shown to modulate the microbiota in vivo by not only significantly changing the abundance and phylotypes of the whole microbiota, but also selectively changing the abundance of some key genera related to the oxidative status of host intestines. These findings also explained the consistent effect of EPS on the diversity of microbiota and oxidative status of the host. The effect of the EPS and fermented milk with L. plantarum YW11 on the changes in key metabolites of gut microbiota closely correlated with the oxidative status and health of mice intestinal tract was further investigated.

\section{Concentrations of $\mathrm{NO}_{x}$ and SCFA in Feces}

Excessive NO represents a factor of oxidative injuries to many visceral organs (Beckman et al., 1990); it is unstable and readily converted into $\mathrm{NO}_{\mathrm{x}}$ (Soleimani et al., 2016), which makes $\mathrm{NO}_{\mathrm{x}}$ a useful index to evaluate the oxidative status of intestinal environment (Coskun Cevher et al., 2015). The effect of different treatments on the concentration of $\mathrm{NO}_{\mathrm{x}}$ in the feces is shown in Figure 6A. Among all the treatment groups, the Dgalactose-treated group had the highest concentration of $\mathrm{NO}_{\mathrm{x}}(194.20 \mu \mathrm{mol} / \mathrm{g})$. The LD $(45.31 \mu \mathrm{mol} / \mathrm{g})$, HD $(19.18 \mu \mathrm{mol} / \mathrm{g})$ and $\mathrm{FM}(53.29 \mu \mathrm{mol} / \mathrm{g})$ treatments reduced $\mathrm{NO}_{\mathrm{x}}$ concentration compared with the normal $(55.10 \mu \mathrm{mol} / \mathrm{g})$ and VC groups $(62.42 \mu \mathrm{mol} / \mathrm{g})$. This significant reducing effect of the $\mathrm{LD}, \mathrm{HD}$, and $\mathrm{FM}$ groups might be due to the effective elimination of Flexispira strains, a reduction of 11.4, 37.5, and 7.6 fold that in the D-galactose-treated group, respectively. Flexispira was found to be closely relate to the members of the genus Helicobacter, which correlated with many types of hepatic disease (Fox et al., 2009). The strains in this family could express inducible nitric oxide synthase to cause the excessive accumulation of $\mathrm{NO}$ in organs, resulting in abdominal viscus injuries (Zhang et al., 2015).

The SCFA-producing genera of Blautia, Butyricicoccus, and Allobaculum also increased remarkably in the groups treated with $\mathrm{VC}, \mathrm{HD}$, and FM. The concentrations of acetic, propionic, and butyric acids in the feces were examined. The concentrations of acetic and butyric acids increased significantly $(P<0.05)$ in the VC (2.30 and $15.15 \mathrm{mg} / \mathrm{g})$, HD (2.91 and $12.92 \mathrm{mg} / \mathrm{g}$ ), and FM (2.43 and $14.18 \mathrm{mg} / \mathrm{g})$ groups compared with D-galactose-treated group. The difference in propionic acid content was not significant between these groups $(P>0.05)$. The SCFA were thought to be the main energy source for intestinal epithelial cells and played a key role in the fortification of gut barrier through activating cell differentiation or participating in tight junction assembly (Cani et al., 2009; Peng et al., 2009). The in vivo gut barrier and protecting effects of plant polysaccharides and yogurt were reported earlier (Huang et al., 2008; Irvine et al., 2010). The change in fecal SCFA in the different treatment groups suggested that the protective function of an HD of EPS produced by L. plantarum YW11 and its fermented milk could be mediated by enriching the SCFA-producing strains in gut microbiota.

The effect of essential foods, including animal protein and fat diets and vegetarian diets, on the levels of health-related microbiota metabolites has been extensively studied. Dietary fiber in vegetarian diets proved 
to be most effective to promote the SCFA production of microbiota (Vipperla and O'Keefe, 2016). This was consistent with the results obtained in our study in
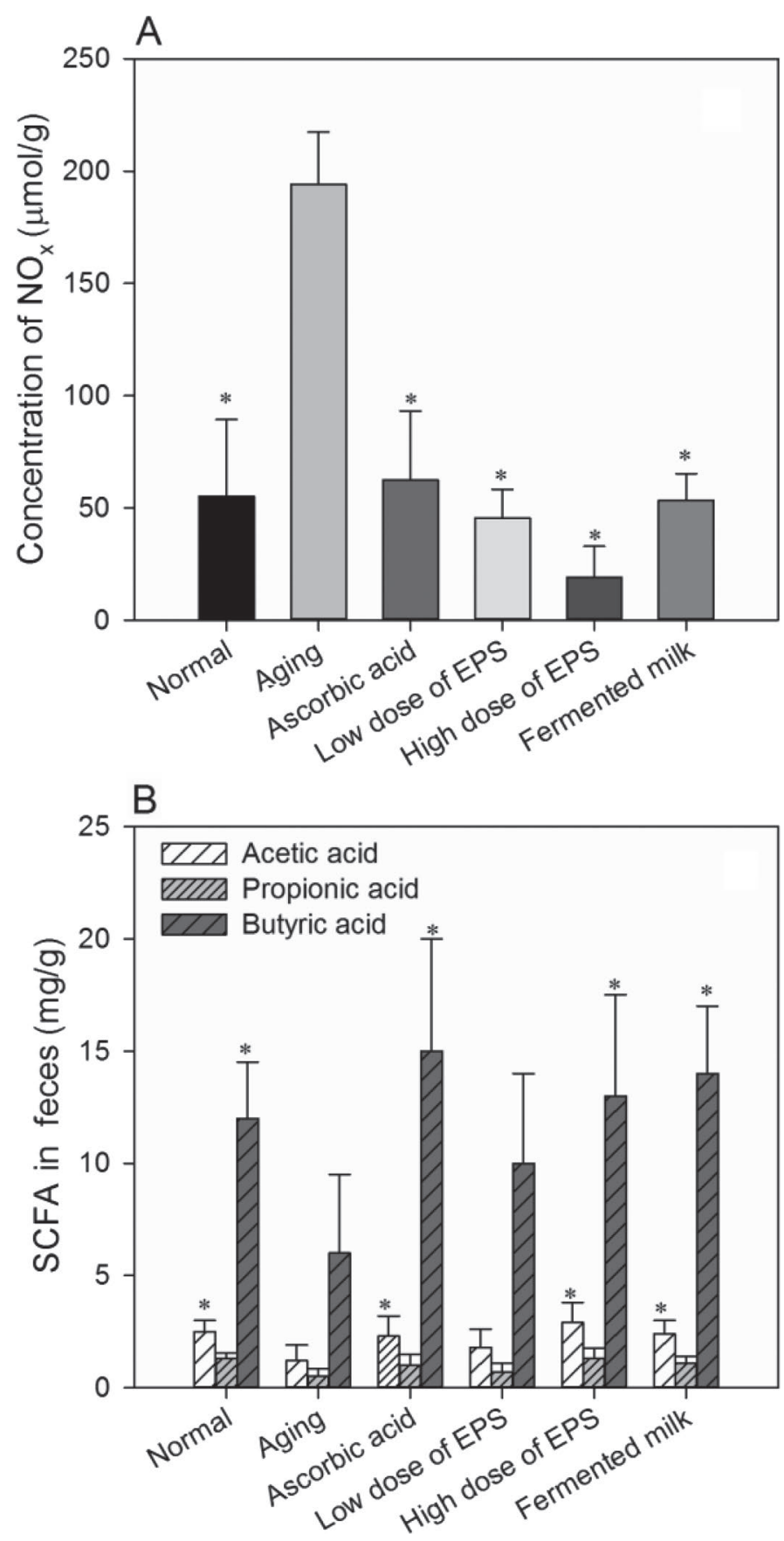

Figure 6. Effect of different treatments on the concentrations of nitrogen oxides $\left(\mathrm{NO}_{\mathrm{x}}, \mathrm{A}\right)$ and short-chain fatty acids (SCFA, B) in the feces of aging mouse model. An asterisk $(*)$ represents a statistically significant difference $(P<0.05)$ comparing the individual group with the aging group assessed by the 1-way ANOVA test. EPS = exopolysaccharide. Bar heights represent the mean values of concentration of SCFA or $\mathrm{NO}_{\mathrm{x}}$; error bars represent the value of SD. the favorable effect of EPS on the SCFA formation in the mice gut. Dietary fiber could also downregulate NO production in trinitrobenzenesulfonic acid-induced colitis (Rodríguez-Cabezas et al., 2002). However, the animal source food was found to increase the abundance of Leishmania, associated with the induction of NO synthases (Lima-Junior et al., 2013). The high-fat diet lowered the effectiveness of NO synthase inhibitor (nitro-L-arginine; Bhattarai et al., 2016); however, a direct evidence of dietary effect on the level of NO in the intestinal tract is still scarce. This novel study reported the regulatory effect of EPS produced by L. plantarum, similar to that of dietary fiber, on the NO and SCFA levels in aging mice intestines, thereby facilitating the recovery of intestinal oxidative status. The correlation of gut microbiota change with other phenotypes (MDA, GSH-Px, SOD, CAT, and T-AOC) more directly reflecting the oxidative status of aging mice was analyzed.

\section{Prediction of Metabolic Phenotypes in a Host via PLS Regression Model}

The PLS regression models were applied to assess the possible associations between the microbiota variations and antioxidant phenotype change in aging mice, using the 232 key OTU determined by previous RDA analysis. As shown by the goodness of prediction $\left(\mathbf{Q}^{2}\right)$ in Table 2, PLS-regression models performed well with CAT $\left(\mathrm{Q}^{2}\right.$ $=0.49)$, T-AOC $\left(\mathrm{Q}^{2}=0.45\right), \mathrm{NO}_{\mathrm{x}}\left(\mathrm{Q}^{2}=0.67\right)$, and SCFA $\left(\mathrm{Q}^{2}=0.55\right)$, indicating that the identified key OTU had a good correlation with the antioxidant phenotype of mice. The prediction quality of the models was also validated by the result of Pearson correlation analysis of the predicted and observed values, especially for CAT $(\mathrm{R}=-0.67)$, T-AOC $(\mathrm{R}=-0.72)$, and SCFA $(\mathrm{R}=-0.81)$ activities. Previously, the oxidativestress metabolic diseases and hypofunction, including colon cancer (Sears and Garrett, 2014), cardiovascular disease (Siti et al., 2015), diabetes (Karunakaran and Park, 2013), obesity (Nistala et al., 2014), and aging (Biagi et al., 2013), were found to have different extent of correlation with gut microbiota (Sanz et al., 2015). However, the conclusions based on human models are controversial mainly due to the long aging process in humans and complex uncertainties during the experiment. A reproducible aging mouse model was employed in our study, and a good correlation of gut microbiota with the oxidative status of D-galactose-induced aging mice was obtained. The mouse was considered as an irreplaceable animal model due to its benefits in the study of the response of gut microbiota to perturbations in a controlled experimental setup testifying causable 
Table 2. Predicted correlation of mice phenotypes with the key OTU using PLS regression model ${ }^{1,2}$

\begin{tabular}{lcrrc}
\hline Item & $\mathrm{Q}^{2}$ & RMSECV & \multicolumn{1}{c}{$\mathrm{r}$} & $P$-value \\
\hline MDA & 0.23 & 2.91 & -0.75 & 0.0086 \\
GSH-Px & 0.18 & 43.71 & 0.22 & 0.0361 \\
SOD & 0.14 & 25.13 & -0.15 & 0.0031 \\
CAT & 0.49 & 3.37 & -0.67 & 0.0148 \\
T-AOC & 0.45 & 3.72 & -0.72 & 0.0107 \\
NO $_{x}$ & 0.67 & 7.81 & -0.66 & 0.0131 \\
SCFA $^{3}$ & 0.55 & 3.72 & 0.81 & 0.0247 \\
\hline
\end{tabular}

${ }^{1} \mathrm{Q}^{2}=$ quality of prediction regressed by leave-one-out cross-validated partial least square regression (PLS); RMSECV = root mean squared error of cross validation; $\mathrm{r}$ and $P$-values are of predicted and observed values.

${ }^{2}$ Key OUT $=$ key operational taxonomic units identified by redundancy analysis; MDA = malondialdehyde; GSH-Px = glutathione peroxidase; $\mathrm{SOD}=$ superoxide dismutase $; \mathrm{CAT}=$ catalase; $\mathrm{T}$-AOC $=$ total antioxidant capacity; $\mathrm{NO}_{\mathrm{x}}=$ nitrogen oxides; $\mathrm{SCFA}=$ shortchain fatty acids.

${ }^{3}$ Total content of acetic, propionic, and butyric acids.

relations (Smits et al., 2013; Brahe et al., 2016; Mai et al., 2016). The results obtained from last 10-yr of studies with an obesity mice model on the relationship of gut microbiota with inflammatory bowel disease and obesity proved effective in humans (Nguyen et al., 2015).

\section{CONCLUSIONS}

The EPS produced by L. plantarum YW11 had a strong antioxidant activity in vitro and in vivo. A high dose of EPS (50 mg/kg per day) effectively relieved the oxidative stress in aging mice, with increased serum levels of GSH-Px, SOD, CAT, and T-AOC, but decreased MDA level. The EPS could effectively recover the diversity and phylotypes decreased or eliminated in the untreated aging mouse model to similar levels as those in the normal mice. The EPS also selectively decreased the abundance of Flexispira and increased the abundance of Blautia and Butyricicoccus, and correspondingly decreased the fecal content of $\mathrm{NO}_{\mathrm{x}}$ and increased the content of SCFA, thereby improving the oxidative and health conditions of the host intestinal tract. Variation of key phylotypes in gut microbiota induced by different doses of EPS treatment had strong correlation with oxidative phenotypes of mice. The fermented milk with $L$. plantarum YW11 containing EPS also showed favorable antioxidant and gut microbiota-regulating activities. The results obtained in this study showed that EPS produced by L. plantarum YW11 could modulate gut microbiota and improve the antioxidant status of the host, contributing to further understanding of the functional mechanism of probiotics and probiotic foods.

\section{ACKNOWLEDGMENTS}

This work was financially supported by the National Natural Science Foundation of China (project number 31371804 and 31571857; Beijing, China), and the China Postdoctoral Science Foundation Funded Project 2015M580939 (Beijing, China).

\section{REFERENCES}

Ahmed, Z., Y. Wang, A. Ahmad, S. T. Khan, M. Nisa, H. Ahmad, and A. Afreen. 2013. Kefir and health: A contemporary perspective. Crit. Rev. Food Sci. Nutr. 53:422-434. https://doi.org/10.1080/1 0408398.2010.540360.

Amaretti, A., M. Di Nunzio, A. Pompei, S. Raimondi, M. Rossi, and A. Bordoni. 2013. Antioxidant properties of potentially probiotic bacteria: In vitro and in vivo activities. Appl. Microbiol. Biotechnol. 97:809-817. https://doi.org/10.1007/s00253-012-4241-7.

Andersen, V., and U. Vogel. 2015. Interactions between meat intake and genetic variation in relation to colorectal cancer. Genes Nutr. 10:448. https://doi.org/10.1007/s12263-014-0448-9.

Archer, J. R., S. Romero, A. E. Ritchie, M. E. Hamacher, B. M. Steiner, J. H. Bryner, and R. F. Schell. 1988. Characterization of an unclassified microaerophilic bacterium associated with gastroenteritis. J. Clin. Microbiol. 26:101-105.

Arumugam, M., J. Raes, E. Pelletier, D. Le Paslier, T. Yamada, D. R. Mende, G. R. Fernandes, J. Tap, T. Bruls, J. Batto, M. Bertalan, N. Borruel, F. Casellas, L. Fernandez, L. Gautier, T. Hansen, M. Hattori, T. Hayashi, M. Kleerebezem, K. Kurokawa, M. Leclerc, F. Levenez, C. Manichanh, H. B. Nielsen, T. Nielsen, N. Pons, J. Poulain, J. Qin, T. Sicheritz-Ponten, S. Tims, D. Torrents, E. Ugarte, E. G. Zoetendal, J. Wang, F. Guarner, O. Pedersen, W. M. de Vos, S. Brunak, J. Dore, J. Weissenbach, S. D. Ehrlich, and P. Bork. 2011. Enterotypes of the human gut microbiome. 473:174-180. https://doi.org/10.1038/nature09944.

Arun, J., S. Selvakumar, R. Sathishkumar, M. Moovendhan, G. Ananthan, T. Maruthiah, and A. Palavesam. 2017. In vitro antioxidant activities of an exopolysaccharide from a salt pan bacterium $\mathrm{Ha}$ lolactibacillus miurensis. Carbohydr. Polym. 155:400-406. https:// doi.org/10.1016/j.carbpol.2016.08.085.

Beckman, J. S., T. W. Beckman, J. Chen, P. A. Marshall, and B. A. Freeman. 1990. Apparent hydroxyl radical production by peroxynitrite: Implications for endothelial injury from nitric oxide and superoxide. Proc. Natl. Acad. Sci. USA 87:1620-1624. https://doi. org/10.1073/pnas.87.4.1620.

Bhattacharjee, N., R. Paul, A. Giri, and A. Borah. 2016. Chronic exposure of homocysteine in mice contributes to dopamine loss by enhancing oxidative stress in nigrostriatum and produces behavioral phenotypes of Parkinson's disease. Biochem. Biophys. Rep. 6:47-53. https://doi.org/10.1016/j.bbrep.2016.02.013.

Bhattarai, Y., D. Fried, B. Gulbransen, M. Kadrofske, R. Fernandes, H. Xu, and J. Galligan. 2016. High-fat diet-induced obesity alters nitric oxide-mediated neuromuscular transmission and smooth muscle excitability in the mouse distal colon. Am. J. Physiol. Gastrointest. Liver Physiol. 311:G210-G220. https://doi.org/10.1152/ ajpgi.00085.2016.

Biagi, E., M. Candela, S. Turroni, P. Garagnani, C. Franceschi, and P. Brigidi. 2013. Ageing and gut microbes: Perspectives for health maintenance and longevity. Pharmacol. Res. 69:11-20. https://doi. org/10.1016/j.phrs.2012.10.005.

Braak, C. J. F. T., and P. Smilauer. 2002. CANOCO Reference Manual and CanoDraw for Windows User's Guide: Software for Canonical Community Ordination. Version 4.5. Cambridge University Press, Oxford, UK.

Brackney, D. E., E. E. Schirtzinger, T. D. Harrison, G. D. Ebel, and K. A. Hanley. 2015. Modulation of flavivirus population diversity by RNA interference. J. Virol. 89:4035-4039. https://doi. org/10.1128/JVI.02612-14. 
Brahe, L. K., A. Astrup, and L. H. Larsen. 2016. Can we prevent obesity-related metabolic diseases by dietary modulation of the gut microbiota? Adv. Nutr. 7:90-101. https://doi.org/10.3945/ an. 115.010587

Cabreiro, F., and D. Gems. 2013. Worms need microbes too: Microbiota, health and aging in Caenorhabditis elegans. EMBO Mol. Med. 5:1300-1310. https://doi.org/10.1002/emmm.201100972.

Cani, P. D., S. Possemiers, T. Van de Wiele, Y. Guiot, A. Everard, O. Rottier, L. Geurts, D. Naslain, A. Neyrinck, and D. M. Lambert. 2009. Changes in gut microbiota control inflammation in obese mice through a mechanism involving GLP-2-driven improvement of gut permeability. Gut 58:1091-1103. https://doi.org/10.1136/ gut.2008.165886.

Chen, Y., H. Zhang, Y. Wang, S. Nie, C. Li, and M. Xie. 2015a. Sulfated modification of the polysaccharides from Ganoderma atrum and their antioxidant and immunomodulating activities. Food Chem. 186:231-238. https://doi.org/10.1016/j.foodchem.2014.10.032.

Chen, Z., J. Shi, X. Yang, B. Nan, Y. Liu, and Z. Wang. 2015b. Chemical and physical characteristics and antioxidant activities of the exopolysaccharide produced by Tibetan kefir grains during milk fermentation. Int. Dairy J. 43:15-21. https://doi.org/10.1016/j. idairyj.2014.10.004.

Claesson, M. J., I. B. Jeffery, S. Conde, S. E. Power, E. M. O. Connor, S. Cusack, H. M. Harris, M. Coakley, B. Lakshminarayanan, and O. O. Sullivan. 2012. Gut microbiota composition correlates with diet and health in the elderly. Nature 488:178-184. https://doi. org/10.1038/nature11319.

Clark, R. I., A. Salazar, R. Yamada, S. Fitz-Gibbon, M. Morselli, J. Alcaraz, A. Rana, M. Rera, M. Pellegrini, and W. J. William. 2015. Distinct shifts in microbiota composition during Drosophila aging impair intestinal function and drive mortality. Cell Reports 12:1656-1667. https://doi.org/10.1016/j.celrep.2015.08.004.

Coskun Cevher, S. C., B. Balabanli, and B. Aslim. 2015. Effects of probiotic supplementation on systemic and intestinal oxidant-antioxidant events in splenectomized rats. Surg. Today 45:1166-1172. https://doi.org/10.1007/s00595-014-1035-9.

Das, D., R. Baruah, and A. Goyal. 2014. A food additive with prebiotic properties of an alpha-d-glucan from Lactobacillus plantarum DM5. Int. J. Biol. Macromol. 69:20-26. https://doi.org/10.1016/j. ijbiomac.2014.05.029

Davì, G., M. Neri, A. Falco, D. Festi, T. Taraborelli, G. Ciabattoni, S. Basili, F. Cuccurullo, and C. Patrono. 2005. Helicobacter pylori infection causes persistent platelet activation in vivo through enhanced lipid peroxidation. Arterioscler. Thromb. Vasc. Biol. $25: 246-251$.

DeSantis, T. Z., P. Hugenholtz, K. Keller, E. L. Brodie, N. Larsen, Y. M. Piceno, R. Phan, and G. L. Andersen. 2006. NAST: a multiple sequence alignment server for comparative analysis of $16 \mathrm{~S}$ rRNA genes. Nucleic Acids Res. 34:W394-9. https://doi.org/10.1093/ nar/gkl244.

Dominguez-Bello, M. G., E. K. Costello, M. Contreras, M. Magris, G. Hidalgo, N. Fierer, and R. Knight. 2010. Delivery mode shapes the acquisition and structure of the initial microbiota across multiple body habitats in newborns. Proc. Natl. Acad. Sci. USA 107:1197111975. https://doi.org/10.1073/pnas.1002601107.

Formichi, P., E. Radi, C. Branca, C. Battisti, J. Brunetti, P. Da Pozzo, F. Giannini, M. T. Dotti, L. Bracci, and A. Federico. 2016. Oxidative stress-induced apoptosis in peripheral blood lymphocytes from patients with POLG-related disorders. J. Neurol. Sci. 368:359-368. https://doi.org/10.1016/j.jns.2016.07.047.

Fox, J. G., Z. Shen, S. Muthupalani, A. R. Rogers, S. M. Kirchain, and F. E. Dewhirst. 2009. Chronic hepatitis, hepatic dysplasia, fibrosis, and biliary hyperplasia in hamsters naturally infected with a novel Helicobacter classified in the H. bilis cluster. J. Clin. Microbiol. 47:3673-3681. https://doi.org/10.1128/JCM.00879-09.

Gagnon, M., P. Savard, A. Rivière, G. LaPointe, and D. Roy. 2015. Bioaccessible antioxidants in milk fermented by Bifidobacterium longum ssp. longum strains. Biomed. Res. Int. 2015:169381. https://doi.org/10.1155/2015/169381.

Gan, F., X. Chen, S. F. Liao, C. Lv, F. Ren, G. Ye, C. Pan, D. Huang, J. Shi, and X. Shi. 2014. Selenium-enriched probiotics improve an- tioxidant status, immune function, and selenoprotein gene expression of piglets raised under high ambient temperature. J. Agric. Food Chem. 62:4502-4508. https://doi.org/10.1021/jf501065d.

Gerrard, J., D. Alfredson, and I. Smith. 2001. Recurrent bacteremia and multifocal lower limb cellulitis due to helicobacter-like organisms in a patient with X-Linked Hypogammaglobulinemia. Clin. Infect. Dis. 33:E116-E118. https://doi.org/10.1086/323405.

Giese, E. C., J. Gascon, G. Anzelmo, A. M. Barbosa, M. A. A. Da Cunha, and R. F. H. Dekker. 2015. Free-radical scavenging properties and antioxidant activities of botryosphaeran and some other $\beta$-D-glucans. Int. J. Biol. Macromol. 72:125-130. https://doi. org/10.1016/j.ijbiomac.2014.07.046.

Glorieux, C., J. M. Sandoval, A. Fattaccioli, N. Dejeans, J. C. Garbe, M. Dieu, J. Verrax, P. Renard, P. Huang, and P. B. Calderon. 2016 Chromatin remodeling regulates catalase expression during cancer cells adaptation to chronic oxidative stress. Free Radic. Biol. Med. 99:436-450. https://doi.org/10.1016/j.freeradbiomed.2016.08.031.

Graham, D. Y., H. Lu, and Y. Yamaoka. 2007. A report card to grade Helicobacter pylori therapy. Helicobacter 12:275-278. https://doi. org/10.1111/j.1523-5378.2007.00518.x.

Green, L. C., D. A. Wagner, J. Glogowski, P. L. Skipper, J. S. Wishnok, and S. R. Tannenbaum. 1982. Analysis of nitrate, nitrite, and [15 N] nitrate in biological fluids. Anal. Biochem. 126:131-138. https://doi.org/10.1016/0003-2697(82)90118-X.

Hamulakova, S., P. Poprac, K. Jomova, V. Brezova, P. Lauro, L. Drostinova, D. Jun, V. Sepsova, M. Hrabinova, O. Soukup, P. Kristian, Z. Gazova, Z. Bednarikova, K. Kuca, and M. Valko. 2016. Targeting copper (II)-induced oxidative stress and the acetylcholinesterase system in Alzheimer's disease using multifunctional tacrine-coumarin hybrid molecules. J. Inorg. Biochem. 161:52-62. https://doi.org/10.1016/j.jinorgbio.2016.05.001.

Ho, S. C., J. Liu, and R. Wu. 2003. Establishment of the mimetic aging effect in mice caused by D-galactose. Biogerontology 4:15-18. https://doi.org/10.1023/A:1022417102206.

Hongpattarakere, T., N. Cherntong, S. Wichienchot, S. Kolida, and R. A. Rastall. 2012. In vitro prebiotic evaluation of exopolysaccharides produced by marine isolated lactic acid bacteria. Carbohydr. Polym. 87:846-852.

Huang, Y. L., G. Yen, F. Sheu, and C. Chau. 2008. Effects of watersoluble carbohydrate concentrate from Chinese jujube on different intestinal and fecal indices. J. Agric. Food Chem. 56:1734-1739. https://doi.org/10.1021/jf072664z.

Irvine, S. L., R. Hummelen, S. Hekmat, C. W. Looman, J. D. F. Habbema, and G. Reid. 2010. Probiotic yogurt consumption is associated with an increase of CD4 count among people living with HIV/AIDS. J. Clin. Gastroenterol. 44:e201-e205. https://doi. org/10.1097/MCG.0b013e3181d8fba8.

Jones, R. M., J. W. Mercante, and A. S. Neish. 2012. Reactive oxygen production induced by the gut microbiota: Pharmacotherapeutic implications. Curr. Med. Chem. 19:1519-1529. https://doi. org/10.2174/092986712799828283.

Karunakaran, U., and K. Park. 2013. A systematic review of oxidative stress and safety of antioxidants in diabetes: Focus on islets and their defense. Diabetes Metab. J. 37:106-112. https://doi. org/10.4093/dmj.2013.37.2.106.

Kristensen, N. B., T. Bryrup, K. H. Allin, T. Nielsen, T. H. Hansen, and O. Pedersen. 2016. Alterations in fecal microbiota composition by probiotic supplementation in healthy adults: A systematic review of randomized controlled trials. Genome Med. 8:52. https:// doi.org/10.1186/s13073-016-0300-5.

Kumar, M., A. Kumar, R. Nagpal, D. Mohania, P. Behare, V. Verma, P. Kumar, D. Poddar, P. K. Aggarwal, and C. Henry. 2010. Cancer-preventing attributes of probiotics: An update. Int. J. Food Sci. Nutr. 61:473-496. https://doi.org/10.3109/09637480903455971.

Kumar, R. S., P. Kanmani, N. Yuvaraj, K. A. Paari, V. Pattukumar, C. Thirunavukkarasu, and V. Arul. 2012. Lactobacillus plantarum AS1 isolated from south Indian fermented food Kallappam suppress 1, 2-dimethyl hydrazine (DMH)-induced colorectal cancer in male Wistar rats. Appl. Biochem. Biotechnol. 166:620-631. https://doi.org/10.1007/s12010-011-9453-2. 
Kusche, D., K. Kuhnt, K. Ruebesam, C. Rohrer, A. F. Nierop, G. Jahreis, and T. Baars. 2015. Fatty acid profiles and antioxidants of organic and conventional milk from low- and high-input systems during outdoor period. J. Sci. Food Agric. 95:529-539. https://doi. org/10.1002/jsfa.6768.

Li, S., and N. P. Shah. 2014. Antioxidant and antibacterial activities of sulphated polysaccharides from Pleurotus eryngii and Streptococcus thermophilus ASCC 1275. Food Chem. 165:262-270. https:// doi.org/10.1016/j.foodchem.2014.05.110.

Li, S., Y. Zhao, L. Zhang, X. Zhang, L. Huang, D. Li, C. Niu, Z. Yang, and Q. Wang. 2012. Antioxidant activity of Lactobacillus plantarum strains isolated from traditional Chinese fermented foods. Food Chem. 135:1914-1919. https://doi.org/10.1016/j. foodchem.2012.06.048

Li, W., J. Ji, X. Chen, M. Jiang, X. Rui, and M. Dong. 2014. Structural elucidation and antioxidant activities of exopolysaccharides from Lactobacillus helveticus MB2-1. Carbohydr. Polym. 102:351359. https://doi.org/10.1016/j.carbpol.2013.11.053.

Li, X., Y. Chen, S. Shao, Q. Tang, W. Chen, Y. Chen, and X. Xu. 2016b. Oxidative stress induces the decline of brain EPO expression in aging rats. Exp. Gerontol. 83:89-93. https://doi.org/10.1016/j. exger.2016.07.012

Lima-Junior, D. S., D. L. Costa, V. Carregaro, L. D. Cunha, A. L. N. Silva, T. W. P. Mineo, F. R. S. Gutierrez, M. Bellio, K. R. Bortoluci, R. A. Flavell, M. T. Bozza, J. S. Silva, and D. S. Zamboni. 2013. Inflammasome-derived IL-1[beta] production induces nitric oxide-mediated resistance to Leishmania. Nat. Med. 19:909-915. https://doi.org/10.1038/nm.3221.

Luang-In, V., and S. Deeseenthum. 2016. Exopolysaccharide-producing isolates from Thai milk kefir and their antioxidant activities. LWT Food Sci. Technol. (Campinas) 73:592-601. https://doi. org/10.1016/j.lwt.2016.06.068.

Mai, V., M. Prosperi, and L. Yaghjyan. 2016. Moving microbiota research toward establishing causal associations that represent viable targets for effective public health interventions. Ann. Epidemiol. 26:306-310. https://doi.org/10.1016/j.annepidem.2016.03.011.

Mishra, V., C. Shah, N. Mokashe, R. Chavan, H. Yadav, and J. Prajapati. 2015. Probiotics as potential antioxidants: A systematic review. J. Agric. Food Chem. 63:3615-3626. https://doi. org/10.1021/jf506326t.

Nguyen, T. L. A., S. Vieira-Silva, A. Liston, and J. Raes. 2015. How informative is the mouse for human gut microbiota research? Dis. Model. Mech. 8:1-6. https://doi.org/10.1242/dmm.017400.

Nistala, R., J. Habibi, A. Aroor, J. R. Sowers, M. R. Hayden, A. Meuth, W. Knight, T. Hancock, T. Klein, and V. G. DeMarco. 2014. DPP4 inhibition attenuates filtration barrier injury and oxidant stress in the zucker obese rat. Obesity (Silver Spring) 22:2172-2179. https://doi.org/10.1002/oby.20833.

Ohata, M., S. Uchida, L. Zhou, and K. Arihara. 2016. Antioxidant activity of fermented meat sauce and isolation of an associated antioxidant peptide. Food Chem. 194:1034-1039. https://doi. org/10.1016/j.foodchem.2015.08.089.

Panat, N. A., D. K. Maurya, S. S. Ghaskadbi, and S. K. Sandur. 2016. Troxerutin, a plant flavonoid, protects cells against oxidative stress-induced cell death through radical scavenging mechanism. Food Chem. 194:32-45. https://doi.org/10.1016/j. foodchem.2015.07.078

Park, J., J. Min, B. Kim, U. Chae, J. W. Yun, M. Choi, I. Kong, K. Chang, and D. Lee. 2015. Mitochondrial ROS govern the LPSinduced pro-inflammatory response in microglia cells by regulating MAPK and NF-кB pathways. Neurosci. Lett. 584:191-196. https://doi.org/10.1016/j.neulet.2014.10.016.

Peng, L., Z. Li, R. S. Green, I. R. Holzman, and J. Lin. 2009. Butyrate enhances the intestinal barrier by facilitating tight junction assembly via activation of AMP-activated protein kinase in Caco-2 cell monolayers. J. Nutr. 139:1619-1625. https://doi.org/10.3945/ jn. 109.104638 .

Perez-Llamas, C., and N. Lopez-Bigas. 2011. Gitools: Analysis and visualisation of genomic data using interactive heat-maps. PLoS One 6:e19541. https://doi.org/10.1371/journal.pone.0019541.
Pham, P. L., I. Dupont, D. Roy, G. Lapointe, and J. Cerning. 2000 Production of exopolysaccharide by Lactobacillus rhamnosus $\mathrm{R}$ and analysis of its enzymatic degradation during prolonged fermentation. Appl. Environ. Microbiol. 66:2302-2310.

Polak-Berecka, M., D. Szwajgier, and A. Waśko. 2014. Biosorption of $\mathrm{Al}^{+3}$ and $\mathrm{Cd}^{+2}$ by an exopolysaccharide from Lactobacillus rhamnosus. J. Food Sci. 79:T2404-T2408. /https://doi.org/10.1111/17503841.12674 .

Prado, M. R. M., C. Boller, R. G. M. Zibetti, D. de Souza, L. L. Pedroso, and C. R. Soccol. 2016. Anti-inflammatory and angiogenic activity of polysaccharide extract obtained from Tibetan kefir. Microvasc. Res. 108:29-33. https://doi.org/10.1016/j. mvr.2016.07.004

Prakash, A., and A. Kumar. 2013. Pioglitazone alleviates the mitochondrial apoptotic pathway and mito-oxidative damage in the d-galactose-induced mouse model. Clin. Exp. Pharmacol. Physiol. 40:644-651. https://doi.org/10.1111/1440-1681.12144.

Rodríguez-Cabezas, M. E., J. Galvez, M. D. Lorente, A. Concha, D. Camuesco, S. Azzouz, A. Osuna, L. Redondo, and A. Zarzuelo. 2002. Dietary fiber down-regulates colonic tumor necrosis factor o and nitric oxide production in trinitrobenzenesulfonic acid-induced colitic rats. J. Nutr. 132:3263-3271.

Sah, B. N., T. Vasiljevic, S. McKechnie, and O. N. Donkor. 2014. Effect of probiotics on antioxidant and antimutagenic activities of crude peptide extract from yogurt. Food Chem. 156:264-270. https://doi.org/10.1016/j.foodchem.2014.01.105.

Santos, J. S., V. R. Alvarenga Brizola, and D. Granato. 2017. Highthroughput assay comparison and standardization for metal chelating capacity screening: A proposal and application. Food Chem. 214:515-522. https://doi.org/10.1016/j.foodchem.2016.07.091.

Sanz, Y., M. Olivares, Á. Moya-Pérez, and C. Agostoni. 2015. Understanding the role of gut microbiome in metabolic disease risk Pediatr. Res. 77:236-244. https://doi.org/10.1038/pr.2014.170.

Schloss, P. D., and J. Handelsman. 2005. Introducing DOTUR, a computer program for defining operational taxonomic units and estimating species richness. Appl. Environ. Microbiol. 71:1501-1506.

Sears, C. L., and W. S. Garrett. 2014. Microbes, microbiota, and colon cancer. Cell Host Microbe 15:317-328. https://doi.org/10.1016/j. chom.2014.02.007.

Serafini, F., F. Turroni, P. Ruas-Madiedo, G. A. Lugli, C. Milani, S. Duranti, N. Zamboni, F. Bottacini, D. van Sinderen, and A. Margolles. 2014. Kefir fermented milk and kefiran promote growth of Bifidobacterium bifidum PRL2010 and modulate its gene expression. Int. J. Food Microbiol. 178:50-59. https://doi.org/10.1016/j. ijfoodmicro.2014.02.024.

Siti, H. N., Y. Kamisah, and J. Kamsiah. 2015. The role of oxidative stress, antioxidants and vascular inflammation in cardiovascular disease (a review). Vascul. Pharmacol. 71:40-56. https://doi. org/10.1016/j.vph.2015.03.005.

Smits, L. P., K. E. Bouter, W. M. de Vos, T. J. Borody, and M. Nieuwdorp. 2013. Therapeutic potential of fecal microbiota transplantation. Gastroenterology 145:946-953. https://doi.org/10.1053/j. gastro.2013.08.058.

Soleimani, N., A. Mohabati Mobarez, M. Tavakoli-Yaraki, and B. Farhangi. 2016. Evaluation of nitric oxide production and proliferation activity of recombinant Bacterioferritin of Helicobacter pylori on macrophages. Microb. Pathog. 100:149-153. https://doi. org/10.1016/j.micpath.2016.07.008.

Strong, W. L. 2016. Biased richness and evenness relationships within Shannon-Wiener index values. Ecol. Indic. 67:703-713. https:// doi.org/10.1016/j.ecolind.2016.03.043.

Thakur, K., S. K. Tomar, B. Brahma, and S. De. 2016. Screening of riboflavin-producing lactobacilli by a polymerase-chain-reactionbased approach and microbiological assay. J. Agric. Food Chem. 64:1950-1956. https://doi.org/10.1021/acs.jafc.5b06165.

Tims, S., C. Derom, D. M. Jonkers, R. Vlietinck, W. H. Saris, M. Kleerebezem, W. M. de Vos, and E. G. Zoetendal. 2013. Microbiota conservation and BMI signatures in adult monozygotic twins. ISME J. 7:707-717. https://doi.org/10.1038/ismej.2012.146. 
Vipperla, K., and S. J. O'Keefe. 2016. Diet, microbiota, and dysbiosis: A 'recipe' for colorectal cancer. Food Funct. 7:1731-1740. https:// doi.org/10.1039/c5fo01276g.

Wang, A. N., X. W. Yi, H. F. Yu, B. Dong, and S. Y. Qiao. 2009. Free radical scavenging activity of Lactobacillus fermentum in vitro and its antioxidative effect on growing-finishing pigs. J. Appl. Microbiol. 107:1140-1148. https://doi.org/10.1111/j.13652672.2009.04294.x.

Wang, J. 2015. Separation, screening, molecular characterization and application of exopolysaccharide-producing Lactobacillus plantarum strains. PhD thesis. Department of Food Science and Engineering, Jilin University, Changchun, China.

Wang, J., X. Zhao, Z. Tian, Y. Yang, and Z. Yang. 2015a. Characterization of an exopolysaccharide produced by Lactobacillus plantarum YW11 isolated from Tibet Kefir. Carbohydr. Polym. 125:16-25. https://doi.org/10.1016/j.carbpol.2015.03.003.

Wang, K., W. Li, X. Rui, T. Li, X. Chen, M. Jiang, and M. Dong. 2015b. Chemical modification, characterization and bioactivity of a released exopolysaccharide (r-EPS1) from Lactobacillus plantarum 70810. Glycoconj. J. 32:17-27. https://doi.org/10.1007/ s10719-014-9567-1.

Wang, T., G. Cai, Y. Qiu, N. Fei, M. Zhang, X. Pang, W. Jia, S. Cai, and L. Zhao. 2012. Structural segregation of gut microbiota between colorectal cancer patients and healthy volunteers. ISME J. 6:320-329. https://doi.org/10.1038/ismej.2011.109.

Wen, T., W. He, Y. Chong, Y. Liu, J. Yin, and X. Wu. 2015. Exploring environment-dependent effects of Pd nanostructures on reactive oxygen species (ROS) using electron spin resonance (ESR) technique: Implications for biomedical applications. Phys. Chem. Chem. Phys. 17:24937-24943. https://doi.org/10.1039/ C5CP04046A.

Wold, S., M. Sjöström, and L. Eriksson. 2001. PLS-regression: A basic tool of chemometrics. Chemom. Intell. Lab. Syst. 58:109-130. https://doi.org/10.1016/S0169-7439(01)00155-1.

Wong, C. N. A., P. Ng, and A. E. Douglas. 2011. Low-diversity bacterial community in the gut of the fruitfly Drosophila melanogaster. Environ. Microbiol. 13:1889-1900. https://doi.org/10.1111/j.14622920.2011.02511.x.
Wu, H., W. Feng, G. Mao, T. Zhao, X. Wu, S. Wang, Y. Zou, L. Yang, and L. Wang. 2016. Long-term supplementation with chromium malate improves short-chain fatty acid content in sprague-dawley rats. Biol. Trace Elem. Res. 174:121-131. https://doi.org/10.1007/ s12011-016-0684-5.

Wu, S., and X. Huang. 2017. Preparation and antioxidant activities of oligosaccharides from Crassostrea gigas. Food Chem. 216:243-246. https://doi.org/10.1016/j.foodchem.2016.08.043.

$\mathrm{Xu}$, R., N. Shang, and P. Li. 2011. In vitro and in vivo antioxidant activity of exopolysaccharide fractions from Bifidobacterium animalis RH. Anaerobe 17:226-231. https://doi.org/10.1016/j. anaerobe.2011.07.010.

Ye, S., F. Liu, J. Wang, H. Wang, and M. Zhang. 2012. Antioxidant activities of an exopolysaccharide isolated and purified from marine Pseudomonas PF-6. Carbohydr. Polym. 87:764-770. https:// doi.org/10.1016/j.carbpol.2011.08.057.

Ye, S., J. Zhang, Z. Liu, Y. Zhang, J. Li, and Y. O. Li. 2016. Biosynthesis of selenium rich exopolysaccharide (Se-EPS) by Pseudomonas PT-8 and characterization of its antioxidant activities. Carbohydr. Polym. 142:230-239. https://doi.org/10.1016/j.carbpol.2016.01.058.

Yin, R., Q. Zhai, L. Yu, Y. Xiao, G. Wang, R. Yu, F. Tian, and W. Chen. 2016. The binding characters study of lead removal by Lactobacillus plantarum CCFM8661. Eur. Food Res. Technol. 242:1621-1629. https://doi.org/10.1007/s00217-016-2661-9.

Yu, X., S. Li, D. Yang, L. Qiu, Y. Wu, D. Wang, N. P. Shah, F. Xu, and H. Wei. 2016. A novel strain of Lactobacillus mucosae isolated from a Gaotian villager improves in vitro and in vivo antioxidant as well as biological properties in d-galactose-induced aging mice. J. Dairy Sci. 99:903-914. https://doi.org/10.3168/jds.2015-10265.

Zhang, H., C. Ding, Z. Suo, and Y. Kang. 2015. Effect of Helicobacter pylori on cyclooxygenase-2 and inducible nitric oxide synthase in patients with gastric precancerous lesions and its clinical significance. Exp. Ther. Med. 9:2364. https://doi.org/10.3892/ etm.2015.2387.

Zhang, L., C. Liu, D. Li, Y. Zhao, X. Zhang, X. Zeng, Z. Yang, and S. Li. 2013. Antioxidant activity of an exopolysaccharide isolated from Lactobacillus plantarum C88. Int. J. Biochem. Cell Biol. 54:270-275. https://doi.org/10.1016/j.ijbiomac.2012.12.037. 